\title{
Resistance Coefficients for Non-Newtonian Flows in Pipe Fittings
}

\author{
Veruscha Fester ${ }^{1}$, Paul Slatter ${ }^{2}$ and Neil Alderman ${ }^{3}$ \\ ${ }^{1}$ Cape Peninsula University of Technology, \\ ${ }^{2}$ Royal Melbourne Institute of Technology, \\ ${ }^{3}$ BHR Group, \\ ${ }^{1}$ South Africa \\ ${ }^{2}$ Australia \\ 3 United Kingdom
}

\section{Introduction}

The focus of this chapter is to provide a review of the loss coefficient data for laminar flow of non-Newtonian fluids in pipe fittings. Since the total pressure change in a piping system generally consists of three components: (i) the frictional pressure loss in the pipe, (ii) the frictional pressure loss arising from flow through fittings and (iii) the pressure loss or gain resulting from elevation changes, this review will also deal with laminar and turbulent pipe flow of non-Newtonian fluids and the application of viscometry for flow in pipes and fittings. The rheological models relevant to industrial fluids such as mine tailings and sewage sludges are introduced, with particular emphasis on yield stress, or viscoplastic, fluids.

Hooper (1981) presented a two-K method for determining the loss coefficient for laminar and turbulent flow through various fittings and valves. This method consists of two factors, one for laminar flow, $K_{1}$ and the other for turbulent flow, $K_{\text {turb }}$. Unlike that for $K_{\text {turb, }}$ there is little data available for $\mathrm{K}_{1}$. Experimental data over the full range of laminar and turbulent flow are presented for flow of Newtonian and non-Newtonian fluids in various fittings. The experimental procedures for the accurate determination of loss coefficients are described.

Current practice for laminar flow through various fittings is to present the loss coefficient as a function of an appropriate Reynolds number. Different Reynolds numbers developed for non-Newtonian fluids have been evaluated to determine their ability to establish the necessary requirement of dynamic similarity for flow of viscoplastic fluids in various fittings.

The laminar to turbulent transition in pipe fittings are also discussed. The experimental work done to date on contractions, expansions, valves and orifices is reviewed in addition to similar work published in literature.

The magnitude of errors that can be obtained using the incorrect loss coefficient is demonstrated by means of a worked example. This chapter will provide the pipeline design 
engineer dealing with non-Newtonian fluids with the necessary information critical for energy efficient design.

\section{Rheological models}

The main types of flow behaviour exhibited by fluids under steady-state shear include:

- Newtonian

- non-Newtonian

- $\quad$ shear-thinning and dilatant (shear-thickening)

- viscoplastic

Over a limited shear rate range (of one or two decades), a fluid can exhibit a single class of behaviour characterised by the flow curves of Sections 2.1, 2.2.1 or 2.2.2. Over a wider shear rate range (within $10^{-6}$ to $10^{6} \mathrm{~s}^{-1}$ ), most fluids exhibit more than one class of flow behaviour.

It is difficult to predict the type of flow behaviour that a fluid will exhibit under given flow conditions (for example, at a given temperature, pressure and concentration). Nevertheless, there are textbooks such as those of Laba (1993) and Steffe (1996) that give examples that can serve as illustrations only. The user should be aware that a rheological test is the only sure method of ascertaining the rheological behaviour of a fluid (Alderman, 1997).

\subsection{Newtonian behaviour}

These are fluids for which an infinitesimal shear stress will initiate flow and for which the shear stress is directly proportional to the shear rate. The flow curve, at a given temperature and pressure, is therefore linear and passes through the origin as is shown in Figure 1(a). The slope of the flow curve, which is constant, is the viscosity. Re-plotting the flow curve in the form of a viscosity curve as shown in Figure 1(b) clearly depicts a constant viscosity with respect to shear rate.

$$
\eta=\frac{\tau}{\dot{\gamma}}
$$

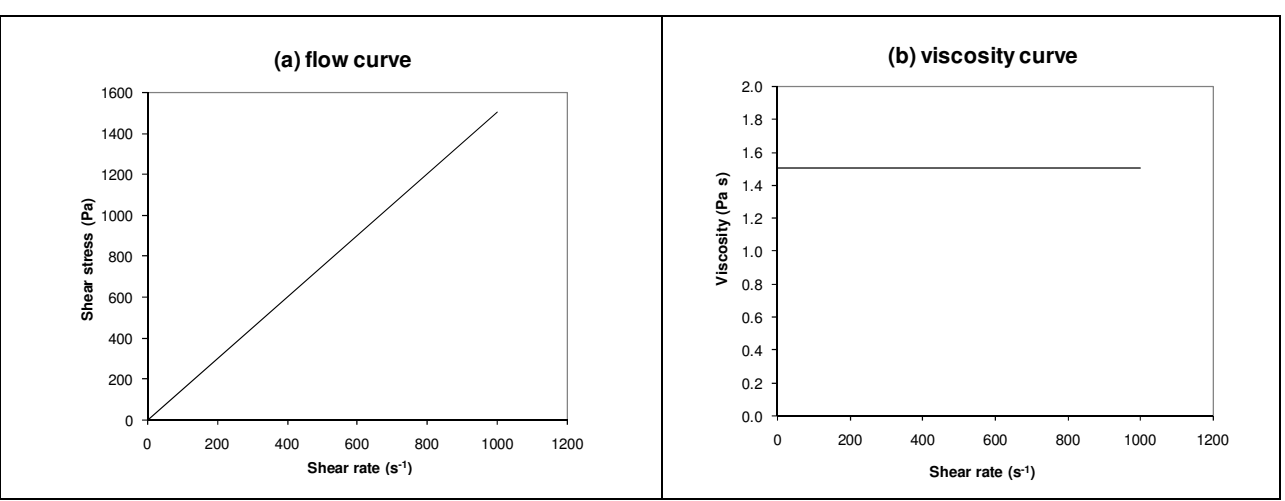

Fig. 1. Flow and viscosity curves for fluids exhibiting Newtonian behaviour

Any deviation from Newtonian behaviour is said to be non-Newtonian. 


\subsection{Non-Newtonian behaviour}

\subsubsection{Shear-thinning and dilatant (shear-thickening) behaviour}

Two departures from Newtonian behaviour, namely shear-thinning and dilatant (shearthickening) behaviour, are depicted in Figure 2.

Shear-thinning behaviour is observed when an infinitesimal shear stress will initiate flow, that is, the flow curve passes through the origin, Figure 2(a) and the viscosity decreases with increasing shear rate as shown in Figure 2(b). This behaviour is sometimes incorrectly termed thixotropy because the equilibrium flow curve of a thixotropic material is often shear-thinning. However, unlike shear-thinning behaviour, thixotropy is a time-dependent property. Dilatant (shear-thickening) behaviour is observed when an infinitesimal shear stress will initiate flow, that is, the flow curve passes through the origin, Figure 2(a) and the viscosity increases with increasing shear rate as shown in Figure 2(b).

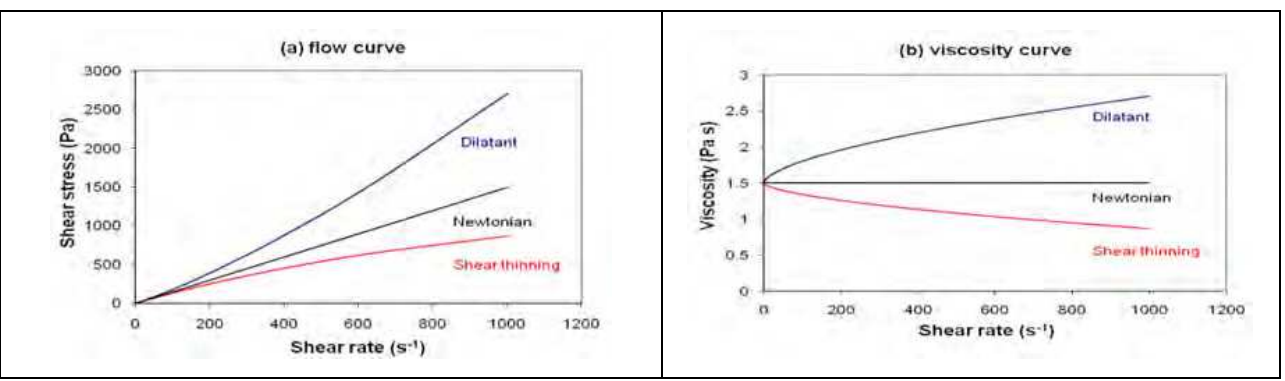

Fig. 2. Idealised shear-thinning and dilatant (shear-thickening) behaviour

For polymeric systems of low concentrations, low molecular weights or at temperatures well above the glass transition temperature, the variation of viscosity with shear rate as a function of concentration, molecular weight or temperature is shown typically in Figure 3.

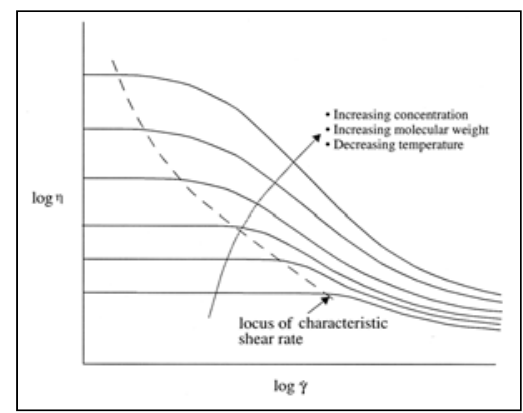

Fig. 3. Non-Newtonian viscosity of polymeric systems of low concentrations, low molecular weight or at temperatures well above the glass transition temperature (Alderman, 1997)

It can be seen that as the concentration or molecular weight is increased or the temperature is decreased, both the zero and infinite shear viscosities, $\eta_{0}$ and $\eta_{\infty}$ increases with the change in the zero shear viscosity being much greater than that for infinite shear viscosity. The 
difference between $\eta_{0}$ and $\eta_{\infty}$ can be very large, as much as two or three orders of magnitude even, if the molecular weight or concentration is sufficiently high. The characteristic shear rate, where the curve starts to deviate from the $\eta_{0}$ line, decreases with increasing concentration or molecular weight or with decreasing temperature. The characteristic shear rate, where the curve starts to deviate from the $\eta_{0}$ line, decreases with increasing concentration or molecular weight or with decreasing temperature.

For particulate systems containing a dispersed phase having negligible inter-particle attraction, the variation of viscosity with shear rate as a function of solids content, shown typically in Figure 4, is complex. At low solids concentrations, the curve depicts shearthinning behaviour with well-defined zero and infinite shear viscosities. The lower boundary of the shear-thinning region can be identified as the curve depicted in Figure 4. At higher solids concentrations, dilatant behaviour is observed at high shear rates. This becomes more pronounced with increasing solids concentration. The characteristic shear rate decreases with increasing concentration until at very high concentrations it falls outside the lowest measurable shear rate. The magnitude of the slope at the characteristic shear rate also increases until at some concentration, it attains a value of -1. If replotted as a flow curve, this would show a yield stress. Here, the flow behaviour is viscoplastic.

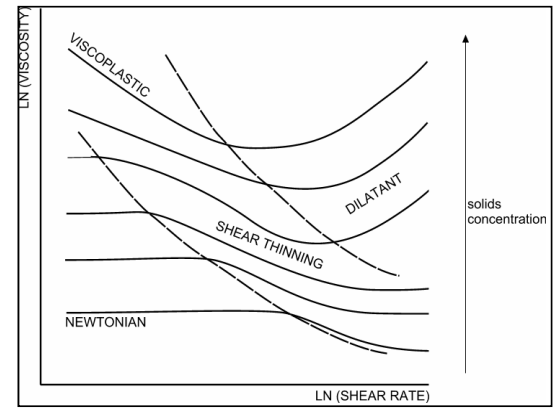

Fig. 4. Non-Newtonian viscosity in suspensions of negligible inter-particle attraction (Alderman, 1997)

\subsubsection{Viscoplastic behavior}

Two further departures from Newtonian behaviour, namely Bingham plastic and viscoplastic behaviour, are depicted in Figure 5. Fluids exhibiting viscoplasticity will sustain a certain shear stress, the yield stress, $\tau_{y}$, without developing continuous flow. For stresses below $\tau_{y}$, the shear rate remains zero whereas for stresses above $\tau_{y}$, the fluid flows with a shear rate dependent on the excess stress $\left(\tau-\tau_{y}\right)$. Bingham plastic behaviour is observed when there is a linear relationship between the shear stress in excess of the yield stress, $\tau_{\mathrm{y}}$ and the resulting shear rate. The flow curve for a Bingham plastic fluid is linear but does not pass through the origin as shown in Figure 5(a). Viscoplastic behaviour is observed when the rate of increase in shear stress with shear rate in excess of the yield stress, $\tau_{\mathrm{y}}$ decreases with increasing shear rate. The flow curve, shown in Figure 5(a), has the same characteristic shape as that for a fluid exhibiting shear-thinning behaviour but does not pass through the origin. The flow curve for both fluids cuts the shear stress-axis above the origin at $\tau_{y}$ on the linear plot, Figure 5(a). The viscosity for both fluids decreases with shear rate 
similar to that for a shear-thinning fluid, Figure 5(b). However, unlike the shear-thinning viscosity which is finite at zero shear rate, the Bingham plastic or viscoplastic viscosity tends to infinity as shear rate is reduced to zero.

Both polymeric and particulate systems can possess a yield stress. This occurs particularly for cross-linked polymers, polymeric gels and filled systems, and for high solids content suspensions and high dispersed phase emulsions and foams. In the case of suspensions, the yield stress arises because of particle-particle frictional interaction. In these materials, it is found that the Bingham plastic behaviour is obtained at high shear rates, as an asymptotic behaviour, Figure 5(a). The intercept of the extrapolated Bingham plastic asymptote is commonly called the Bingham yield stress, $\tau_{\mathrm{yB}}$, to distinguish it from the yield stress, $\tau_{\mathrm{y}}$.

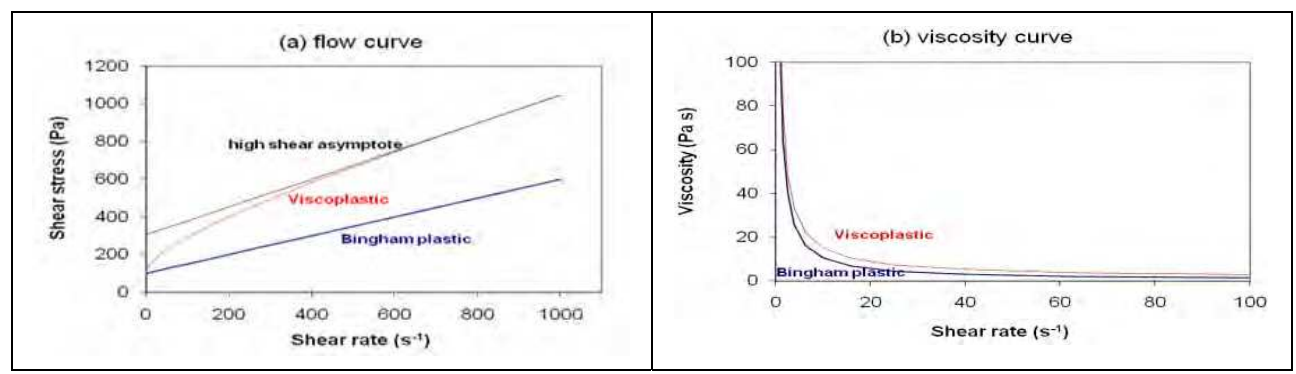

Fig. 5. Idealised Bingham plastic and viscoplastic behaviour

\subsection{Viscosity and flow curve models}

Fluids exhibiting Newtonian behaviour have constant viscosities as defined by Eqn. (1), and single point measurement at a convenient shear rate is sufficient to describe such a fluid. However, non-Newtonian fluids have viscosities that are shear rate-dependent, and a single point measurement is inadequate to describe the flow behaviour. Here, the relevant shear rate range in the engineering application must be assessed and used in determining the measurement conditions for the viscometer/rheometer. Shear ratedependent viscosity is often referred to as apparent viscosity, $\eta_{a}$, but there is no need to make this distinction if it is accepted that viscosity, as defined in Eqn. (1), can be variable. However, it is essential that values of $\eta$ are quoted with their corresponding values of shear rate (or shear stress).

The flow curve or viscosity curve data obtained from viscometric measurements under steady-state shear can be described mathematically in terms of rheological models (constitutive equations) and are amenable to curve fitting. The general form of a rheological model is fitted over a relevant shear rate range to the flow curve or the viscosity curve by least-squares regression analysis so that a specific rheological model can be obtained. This specific equation is then used for material characterization, engineering design applications or product formulation.

The rheological model for Newtonian fluids contains just one constant, $\eta_{N}$. Many models have been proposed to describe the non-Newtonian flow behaviour of fluids, although the majority of these are of little value for engineering design applications and serve more as theoretical analyses. 
In general, the simpler models (for example, Newtonian, Bingham plastic and power law) are used for fitting narrow shear rate ranges (say, one decade), giving straight lines on linear or logarithmic plots. Other models such as Herschel-Bulkley (1926) and Casson (1959) for two or three decades and Sisko (1958) for four decades or more are better for wider shear rate ranges. For the widest shear rate range achievable in practice (that is, $10^{-6}$ to $10^{6} \mathrm{~s}^{-1}$ ), it is necessary to use a more complex model such as the Cross (1965) model or the Carreau (1968) model.

Of the numerous rheological models available in the literature, the most commonly-used for engineering applications are described here.

\subsubsection{Newtonian model}

This is the simplest of all flow curve models and is given by

$$
\tau=\eta_{\mathrm{N}} \dot{\gamma}
$$

with $\eta_{N}$ being the Newtonian viscosity.

\subsubsection{Power law model}

This model originally proposed by de Waele (1923) and Ostwald (1925) is described by the two-parameter equation:

$$
\tau=\mathrm{K} \dot{\gamma}^{\mathrm{n}}
$$

where $\mathrm{K}$ is the consistency coefficient in units of $\mathrm{Pas}^{\mathrm{n}}$ and $\mathrm{n}$ is the power law exponent. This equation can be used to describe Newtonian behaviour when $n=1$, shear-thinning behaviour when $n<1$ or dilatant behaviour when $n>1$. On a log-log plot, the model is a straight line with a slope of $n$. Values of $n$ typically ranges from 0.2 to about 1.4 . The further the value of $\mathrm{n}$ is from unity, the more non-Newtonian is the fluid.

\subsubsection{Bingham plastic model}

This two parameter model (Bingham, 1922) is described by

$$
\tau=\tau_{\mathrm{yB}}+\eta_{\mathrm{B}} \dot{\gamma}
$$

where $\tau_{\mathrm{yB}}$ is the Bingham yield stress and $\eta_{\mathrm{B}}$ is the Bingham plastic viscosity.

\subsubsection{Herschel-Bulkley model}

This model also known as the generalised Bingham plastic model, is a three parameter yield/power law model (Herschel-Bulkley, 1926), given by

$$
\tau=\tau_{\mathrm{yHB}}+\mathrm{K} \dot{\gamma}^{\mathrm{n}}
$$

where $\tau_{\mathrm{yHB}}$ is the Herschel-Bulkley yield stress. This equation describes viscoplastic behaviour when $n<1$. Because power law $\left(\tau_{\mathrm{yHB}}=0\right.$; shear-thinning when $\mathrm{n}<1$ or dilatant when $n>1)$, Newtonian $\left(\tau_{\mathrm{yHB}}=0\right.$ and $\left.n=1\right)$ and Bingham plastic behaviour $(n=1)$ can be 
regarded as special cases, the model represents the flow behaviour of a wide range of fluids without being too difficult to handle mathematically.

\subsubsection{Casson model}

A popular alternative to the Herschel-Bulkley model is the theoretical two-parameter model of Casson (1959). This is given by

$$
\sqrt{\tau}=\sqrt{\tau_{\mathrm{yC}}}+\sqrt{\eta_{\mathrm{C}} \dot{\gamma}}
$$

where $\tau_{\mathrm{yC}}$ is the Casson yield stress and $\tau_{\mathrm{C}}$ is the Casson viscosity.

\subsection{Viscosity and flow curve measurement}

Commercial viscometers and rheometers employ a wide range of geometries for viscosity and flow curve measurement. These can be grouped into two main types: rotational viscometers and tube viscometers.

\subsubsection{Rotational viscometers}

Rotational viscometers, which rely on rotational motion to achieve simple shear flow, can be operated either in the controlled rate or controlled stress mode. In controlled-rate instruments, there are two methods of applying the rotation and measuring the resultant torque. The first method is to rotate one member and measure the torque exerted on the other member by the test sample, whilst the second method involves the rotation of one member and measuring the resultant torque on the same member, The rotating member is either at constant speed which can be sequentially stepped or with a steadily-changing speed ramp. The resultant torque is measured by a torsion spring. In controlled-stress instruments, either a constant torque (which can be sequentially changed) or a torque ramp is applied to the member, and the resultant speed is measured. The more common geometries used in rotational viscometry are shown in Figure 6.

\subsubsection{Tube viscometers}

Tube viscometers are generally once-through batch devices consisting of either a horizontal or vertical length of precision-bored, straight tube through which the test fluid is passed at varying rates from a reservoir. The diameters of the tube can typically range from 1 to $5 \mathrm{~mm}$. Essentially, there are two types of tube viscometer, the controlled flow rate and the controlled pressure, as shown in Figure 7.

In the controlled flow rate tube viscometer, a piston forces the fluid through a horizontal or vertical tube at a constant flow rate and the resultant pressure drop is measured. In the controlled pressure viscometer, compressed air (or nitrogen) is applied to drive the fluid through a horizontal or vertical tube and the resultant volumetric flow rate is measured.

\subsubsection{Practical considerations}

Flow curve measurements can be made using all of these geometries but there are several drawbacks for each geometry which need to be considered for each fluid under test and 
each specific application. Guidance on the use of these geometries for obtaining relevant viscometric data required for a particular application is given by Alderman and Heywood (2004a, 2004b).

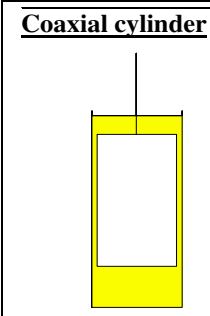

(a) Bob-in-cup

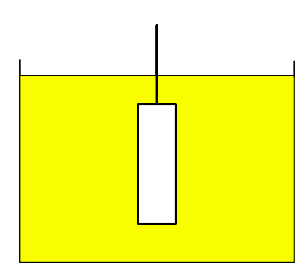

(b) single bob

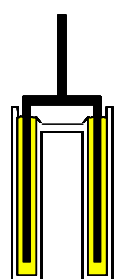

(c) Moore-Davis

\section{Rotating disc}

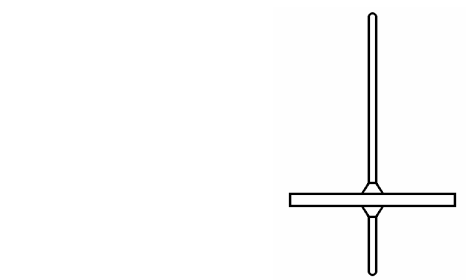

The simplest geometry (a) consists of a bob (inner cylinder) located in a cup (outer cylinder) with the test sample contained in the narrow annular gap between the bob and the cup. Other variations of the coaxial cylinder viscometer that are commonly used include (b) a bob rotating in a large container that approximates to the "infinite sea" situation (that is, the container to bob radius ratio is at least 10 and (c) the MooreDavis double cylinder viscometer used for low viscosity fluids.

This consists of a disc rotating in a large container (normally a $600 \mathrm{ml}$ plastic beaker with an internal diameter of $97 \mathrm{~mm}$ ) of test material. The torque exerted by the test fluid on the rotating disc is measured as a function of rotational speed.
Cone-and-plate

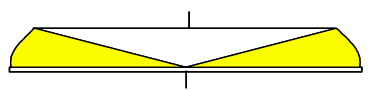

(a) Cone and plate

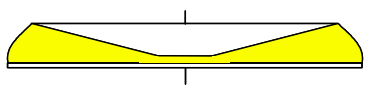

(b) Truncated cone and plate

Usually, the sample under test is contained between the exterior angle of a cone and a flat plate, (a). The axis of the cone is set normal to the plate with the cone apex touching the plate. Cone angles typically range from 0.25 to $1^{\circ}$. However, for solid/liquid suspensions and emulsions, a cone with a truncated apex (b) is often used to minimise problems due to particle jamming.

In controlled-rate instruments, either the cone or the plate is rotated at a fixed speed and the resultant torque via the cone is measured. In controlled-stress instruments, a fixed torque or a torque ramp is applied to the cone and the resultant speed is measured.

\section{$\underline{\text { Parallel plate }}$}

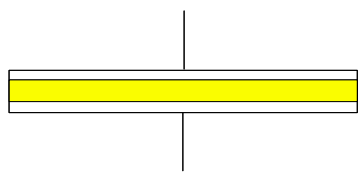

The sample under test is held in the gap between two identical circular flat plates. The gap between the two plates can be varied, typically up to $5 \mathrm{~mm}$ for plates of about $25 \mathrm{~mm}$ radius.

In controlled-rate instruments, either the top or bottom plate is rotated at a fixed speed and the resultant torque is measured. In controlled-stress instruments, a constant torque or a torque ramp is applied to the top plate and the resultant speed is measured.

Fig. 6. Types of rotational viscometer 


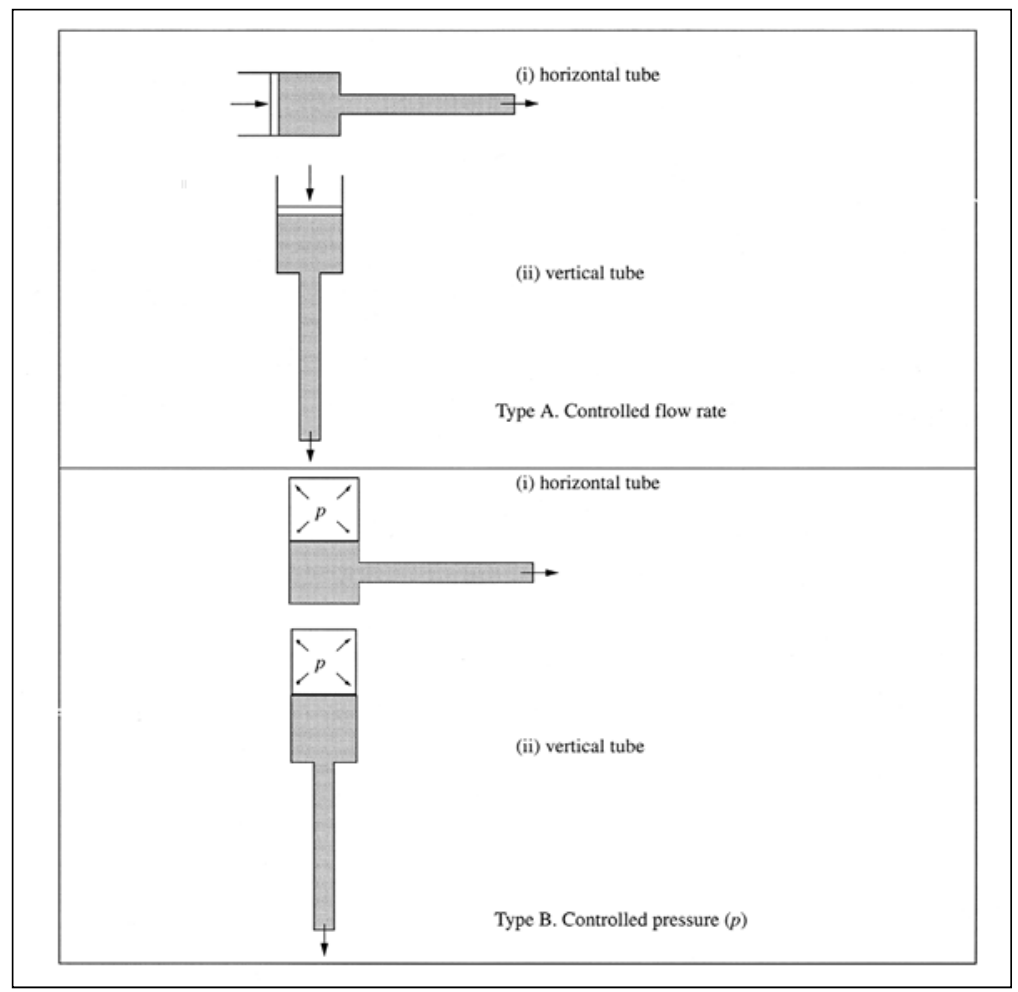

Fig. 7. Types of tube viscometer

For the correct end-use of viscometric data in any processing application, the flow curve must be measured under appropriate conditions of temperature and shear. Hence, the shear rate (or shear stress) to be covered by the viscometer should be matched to that applicable to the particular flow process. With the range of viscometers commercially available, it is technically possible to measure viscosity over 12 orders of magnitude of shear rate from $10^{-6}$ to $10^{6} \mathrm{~s}^{-1}$. However, most processing applications require viscosity data over no more than two or three orders of magnitude of shear rate. Shear rates typical of some flow processes can be found in Alderman and Heywood (2004a). There are quick and simple methods available for defining the shear rate range for any processing application, Alderman and Heywood (2004a). If a method for shear rate estimation in some processing applications is not available, a useful approach is to define the flow region of interest, determine differences in fluid velocity at two points across the region (this will often be the surface of some moving element such as a pump impeller or mixer agitator) and divide this velocity difference by the distance of separation between the two points. These typical shear rates can be used as a basis for choosing a viscometer.

As the equations for calculating the shear stress, shear rate and viscosity assume the flow in the viscometer is laminar, a check must be made to ensure the validity of the viscometric data. Details on how this is done are outlined in Alderman and Heywood (2004b). 


\subsection{Viscosity and flow curve data generation and interpretation}

Figure 8 summarises the key steps to ensuring the measurements of the flow curve are both accurate and relevant (Alderman and Heywood, 2004a; 2004b).The need for accuracy may sometimes introduce additional laboratory experiments, particularly if end effect and/or wall slip errors are incurred. However, ensuring that only the viscometric data that are relevant to the application of interest are measured will minimise the overall effort. Having selected the most appropriate viscometer for the sample under test and the application of interest, the next step is to generate the flow curve.

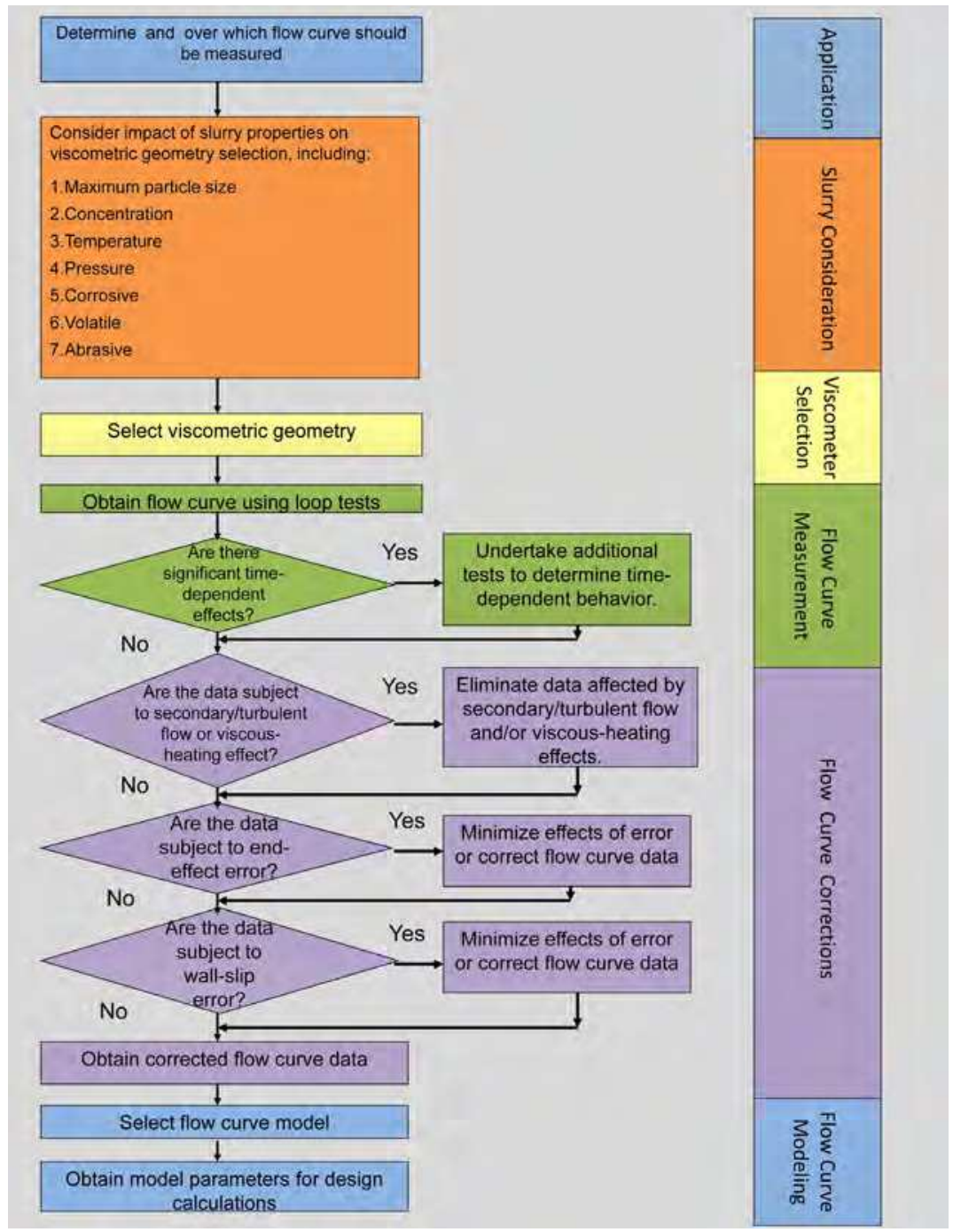

Fig. 8. Flowchart for making accurate and relevant flow curve measurements (Alderman and Heywood, 2004b) 


\subsubsection{Rotational viscometers}

With controlled rate rotational instruments, the flow curve measurement is usually done by carrying out at least three cycles of a fixed time where the speed is varied, either by a sequence of step speed changes or a steadily-changing speed ramp, between minimum and maximum values whilst measuring the resultant torque. With controlled stress rotational instruments, the torque is varied in a similar manner whilst the resultant speed is measured. The time over which the speed or torque is varied is left to the operator to decide. However, a good starting point would be the time that gives $30 \mathrm{~s}$ per step.

Repeated shear cycles on the test sample will enable one to determine whether the sample exhibits time-dependent flow behaviour such as thixotropy. If the up and down curves for the first and successive cycles coincide, the sample is undergoing steady-state shear. However, if hysteresis loops between the up and down curves are observed for each successive cycle, the sample is exhibiting time-dependent flow behaviour. In such cases, it is advisable to repeat the experiment with the speed (or torque) held constant until the torque (or speed) attains a steady value before changing the speed (or torque) to the next value. This will yield an equilibrium flow curve in which the up and down curves coincide.

The average of the torque versus speed data at which the up and down curves coincide is the first step of the calculation procedure for obtaining the corrected flow curve. Care must be taken to ensure that the flow curve is not affected by the four error sources: secondary/turbulent flow, viscous heating, end effect and wall slip. Further details of this procedure can be found in Alderman and Heywood (2004b) for the appropriate viscometric geometry used.

\subsubsection{Tube viscometers}

With controlled-rate tube viscometers (Type A in Figure 7), the flow curve is obtained by carrying out pressure drop measurements at different constant flow rates. For each measurement, a new sample is often required due to the small capacity of the sample reservoir. With controlled-stress tube viscometers (Type B in Figure 7), the flow curve is generated by measuring the flow rate as a function of pressure drop on the sample. The pressure drop versus flow rate data is the first step of the calculation procedure for obtaining the corrected flow curve. Care must be taken to ensure that the flow curve is not affected by the four error sources: secondary/turbulent flow, viscous heating, end effect and wall slip. Further details of this procedure can be found in Alderman and Heywood (2004b).

\subsection{Viscosity and flow curve interpretation for engineering design}

Having completed the calculation procedure for the corrected flow curve (and hence the corrected viscosity curve), the data may be amenable to a single curve fit (Brown \& Heywood, 1991). Sometimes, because of considerable scatter in the data, it may be more appropriate to construct at least two curves: a mean curve obtained from regression analysis using all the data and an upper bound curve obtained from regression analysis using $(\tau, \dot{\gamma})$ data selected from the curve that was initially drawn by eye. The upper bound curve would normally represent the worst case for many engineering applications and would lead to a conservative design. Further factors can cause difficulties in attempting to draw a single flow curve through the data. These factors include the use of two or more different 
viscometric geometries which may give differing degrees of phase separation during shear, sample variability taken from the same batch, and uncorrected errors associated with the use of any viscometric geometry.

For engineering design, the choice of flow curve model is limited by the design method to be used. For example, if the flow curve is to be used for pipeline design, the choice can be made from a number of models including Newtonian, power law, Bingham plastic, Cassonand Herschel Bulkley models. However if the flow curve is to be used for agitation in stirred tanks, the choice is either the Newtonian or the power law model. It is often not immediately obvious from the data which of the flow models should be selected. A decision will need to be made on which model to use. The following approach is suggested:

i. Plot all the $(\tau, \dot{\gamma})$ data on linear axes and separately, on double logarithmic axes. This is to assess the suitability of the Newtonian, Bingham plastic and power law models.

ii. If there is considerable scatter in the data, decide by eye or from the correlation coefficient obtained by linear regression analysis whether a straight line through the linear or the log-log plot gives the better representation. Similarly decide for the upper bound curve. If one of these alternatives is acceptable, the use of the Herschel-Bulkley model is probably not warranted.

iii. If neither of these alternatives appears satisfactory because there is significant curvature of the data on both linear and log-log plots, the following can arise:

a. If there is data curvature on the log-log plot with the slope of the curve increasing with shear rate axis and if the linear plot does not produce a straight line then the Herschel-Bulkley model should adequately describe the data.

b. If there is data curvature on the log-log plot and the slope of the curve decreasing with shear rate axis, then the use of the Herschel-Bulkley model is inappropriate as this implies a negative yield stress parameter. However, a curve fit is possible and would result in a negative value for the yield stress parameter. Force-fit either a Bingham plastic or power law model to the data.

Estimates need to be made for the parameters defined in the flow models. As the HerschelBulkley model can be reduced to the Newtonian, power law and Bingham plastic models, a least squares regression analysis can first be performed on the $(\tau, \dot{\gamma})$ data to obtain $\tau_{\mathrm{yHB}}, \mathrm{K}$ and $\mathrm{n}$. It may then be possible to simplify the model by setting the $\tau_{\mathrm{yHB}}$ to zero if the estimate is close to zero and/or setting $\mathrm{n}$ to 1 if the estimate is close to unity.

Two methods are commonly used when carrying a regression analysis on the $(\tau, \dot{\gamma})$ data (Heywood \& Cheng, 1984):

1. a non-linear least squares regression on unweighted data,

2. a non-linear least squares regression on weighted data.

In Method 1 it is assumed that the error e lies in $\tau$ :

$$
\tau=\tau_{\mathrm{yHB}}+\mathrm{K} \dot{\gamma}^{\mathrm{n}}+\mathrm{e}
$$

whereas in Method 2, the error is assumed to lie in $\ln \left(\tau-\tau_{\mathrm{yHB}}\right)$ :

$$
\ln \left(\tau-\tau_{\mathrm{yHB}}\right)=\ln \mathrm{K}+\mathrm{n} \ln \dot{\gamma}+\mathrm{e}
$$


Standard non-linear regression software packages can be used in either case. Alternatively, non-linear regression can be performed using Microsoft Excel via the 'Solver' tool (Roberts et al., 2001). Both methods will provide sets of $\tau_{\mathrm{yHB}}, K$ and $n$ estimates which give viscometric data predictions to $\pm 2 \%$ of the original data within the original shear rate range. Outside this shear rate range, agreement can be poor.

Examples of the extrapolated flow curves for the two sets of parameters obtained in the two regression methods are shown in Figure 9. Provided the relevant shear rate/shear stress window for the application is covered by the viscometer, either of the two regression methods can be used. However, the method that gives the most uniform data spread should be used.

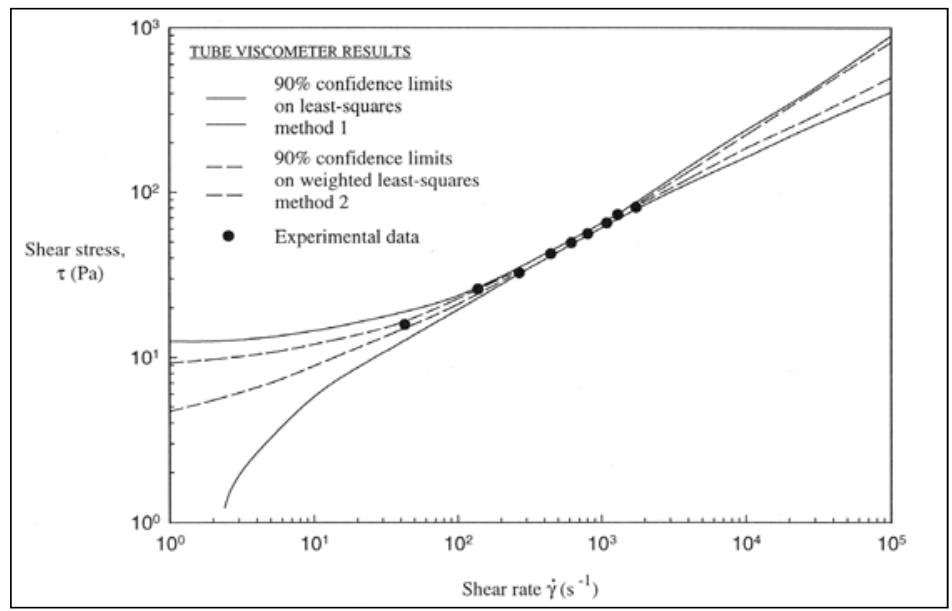

Fig. 9. Example of extrapolation of predicted $(\tau, \dot{\gamma})$ data outside the experimental range for an $8.0 \%$ digested sewage sludge (Heywood and Cheng, 1984)

\section{Pipe flow fundamentals}

The basic relationships for design in laminar, transitional and turbulent pipe flow are obtained by integration of the constitutive rheological relationship, over the cross-sectional area of the pipe.

\subsection{Rheological approach}

Industrial fluids exhibiting viscoplastic behaviour are often best modelled using the Herschel-Bulkley model (Govier \& Aziz, 1972 and Hanks, 1979). The constitutive rheological equation is given by Eqn. (5).

\subsection{Laminar flow}

Equations for the design of laminar pipe flow can be derived by integrating Eqn. (5) over the circular pipe geometry (Govier \& Aziz, 1972). Because of the yield stress, a central solid plug is formed where the point shear stress is less than the yield stress, as shown in Figure 10. 


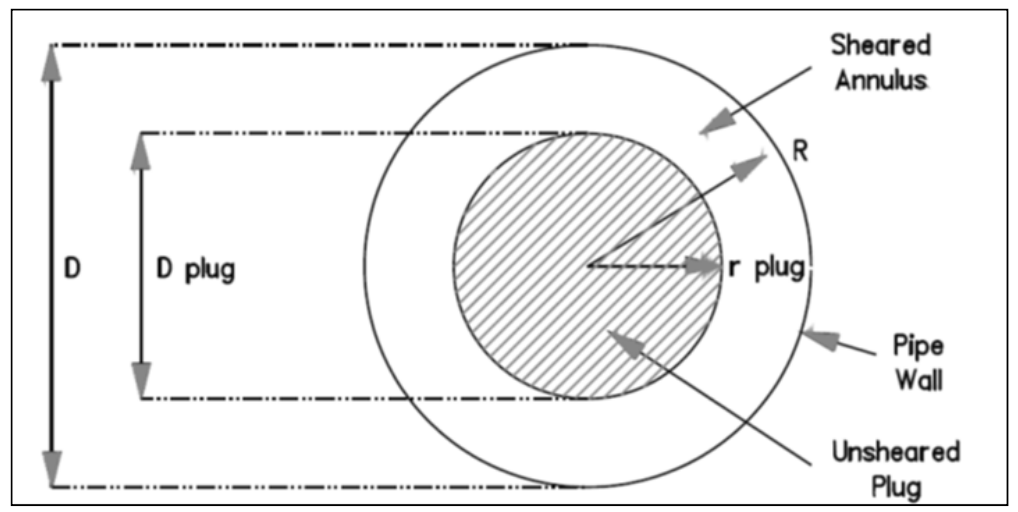

Fig. 10. Schematic showing the geometry of the unsheared plug

The radius of the plug is determined from the linear shear stress distribution and the yield stress as

$$
\mathrm{r}_{\text {plug }}=\frac{\tau_{\mathrm{y}}}{\tau_{0}} \mathrm{R}
$$

In the annular region where the point shear stress exceeds the yield stress, the point velocity $\mathrm{u}$ is obtained by integration of the constitutive rheological relationship, and applying the noslip assumption at the pipe wall

$$
\mathrm{u}=\frac{\mathrm{R}}{\mathrm{K}^{\frac{1}{\mathrm{n}}} \tau_{0}} \frac{\mathrm{n}}{\mathrm{n}+1}\left[\left(\tau_{0}-\tau_{\mathrm{y}}\right)^{\frac{\mathrm{n}+1}{\mathrm{n}}}-\left(\tau-\tau_{\mathrm{y}}\right)^{\frac{\mathrm{n}+1}{\mathrm{n}}}\right] .
$$

The plug velocity $\mathrm{u}_{\text {plug }}$ is obtained at the point where the applied shear stress is equal to the yield stress as

$$
\mathrm{u}_{\mathrm{plug}}=\frac{\mathrm{R}}{\mathrm{K}_{\mathrm{n}}^{\frac{1}{\mathrm{n}}} \tau_{0}} \frac{\mathrm{n}}{\mathrm{n}+1}\left(\tau_{0}-\tau_{\mathrm{y}}\right)^{\frac{\mathrm{n}+1}{\mathrm{n}}} .
$$

These two velocity distributions are integrated over the pipe cross-sectional area appropriate to each, in order to yield the total volumetric flow rate $\mathrm{Q}$ as

$$
\frac{32 \mathrm{Q}}{\pi \mathrm{D}^{3}}=\frac{8 \mathrm{~V}}{\mathrm{D}}=\frac{4 \mathrm{n}}{\mathrm{K}^{1 / \mathrm{n}} \tau_{0}^{3}}\left(\tau_{0}-\tau_{\mathrm{y}}\right)^{\frac{1+\mathrm{n}}{\mathrm{n}}}\left[\frac{\left(\tau_{0}-\tau_{\mathrm{y}}\right)^{2}}{1+3 \mathrm{n}}+\frac{2 \tau_{\mathrm{y}}\left(\tau_{0}-\tau_{\mathrm{y}}\right)}{1+2 \mathrm{n}}+\frac{\tau_{\mathrm{y}}^{2}}{1+\mathrm{n}}\right]
$$

This relationship can be used for laminar pipe flow design.

\subsection{Transitional flow}

The approach used here for the prediction of the transition from laminar to turbulent flow is the modified Reynolds number $\operatorname{Re}_{3}$ (Slatter, 1995; Slatter, 1999). This approach predicts a 
laminar to turbulent transition in the Reynolds number region of 2100. This approach was specifically developed to place emphasis on the viscoplastic nature of the material (Slatter, 1995). Using the fundamental definition that $\operatorname{Re} \propto$ inertial/viscous forces, the final expression is

$$
\operatorname{Re}_{3}=\frac{8 \rho \mathrm{V}_{\mathrm{ann}}{ }^{2}}{\tau_{\mathrm{y}}+\mathrm{K}\left(\frac{8 \mathrm{~V}_{\mathrm{ann}}}{\mathrm{D}_{\text {shear }}}\right)^{\mathrm{n}}}
$$

As shown in Figure 10, in the presence of a yield stress the central core of the fluid moves as a solid plug which fundamentally affects the stability of flow (Slatter, 1995, 1999). The unsheared plug is treated as a solid body in the centre of the pipe. The flow that the plug represents must be subtracted as it is no longer being treated as part of the fluid flow. The corrected mean velocity in the annulus $\mathrm{V}_{\mathrm{ann}}$ is then obtained as follows:-

$$
\mathrm{V}_{\mathrm{ann}}=\frac{\mathrm{Q}_{\mathrm{ann}}}{\mathrm{A}_{\mathrm{ann}}}=\frac{\mathrm{Q}-\mathrm{Q}_{\text {plug }}}{\pi\left(\mathrm{R}^{2}-\mathrm{r}_{\text {plug }}^{2}\right)}
$$

and

$$
\mathrm{Q}_{\text {plug }}=\mathrm{u}_{\text {plug }} \mathrm{A}_{\text {plug }}
$$

The sheared diameter, $\mathrm{D}_{\text {shear, }}$ is taken as the characteristic dimension because this represents the zone in which shearing of the fluid actually takes place, and it is defined as

$$
\mathrm{D}_{\text {shear }}=\mathrm{D}-\mathrm{D}_{\text {plug }}
$$

and

$$
\mathrm{D}_{\text {plug }}=2 \mathrm{r}_{\text {plug }}
$$

These relationships can be used for pipe flow design to determine the transition from laminar to turbulent flow.

\subsection{Turbulent flow}

The approach used here is the particle roughness turbulence approach (Slatter, 1996, 1999b, 2011). The point of departure of this approach is the classical logarithmic velocity distribution

$$
\frac{\mathrm{u}}{\mathrm{V}^{*}}=\mathrm{A} \ln \left(\frac{\mathrm{y}}{\mathrm{d}_{\mathrm{x}}}\right)+\mathrm{B}
$$

The value of $A$ is taken as the inverse of the von Karman universal constant, $A=1 / X=2.5$. $B$ is the classical roughness function (Schlichting, 1960). Integrating and rearranging we get the mean velocity $\mathrm{V}$ as

$$
\frac{\mathrm{V}}{\mathrm{V}^{*}}=\frac{\mathrm{A}}{\chi} \ln \left(\frac{\mathrm{R}}{\mathrm{d}_{85}}\right)+\mathrm{B}-3.75
$$

For smooth wall turbulent flow, this reduces to 


$$
\frac{\mathrm{V}}{\mathrm{V}^{*}}=2.5 \ln \left(\frac{\mathrm{R}}{\mathrm{d}_{85}}\right)+2.5 \ln \mathrm{Re}_{\mathrm{r}}+1.75
$$

For fully developed rough wall turbulent flow, this reduces to

$$
\frac{\mathrm{V}}{\mathrm{V}^{*}}=2.5 \ln \left(\frac{\mathrm{R}}{\mathrm{d}_{85}}\right)+4.75
$$

which will yield a constant value for the Fanning friction factor, $\mathrm{f}$

$$
\frac{1}{\sqrt{\mathrm{f}}}=4.07 \log \left(\frac{3.34 \mathrm{D}}{\mathrm{d}_{85}}\right)
$$

\section{Minor losses in pipe systems}

Head losses, in addition to those due to straight pipe friction, are always incurred at pipe bends, junctions, contractions, expansions and valves. These additional losses are due to eddy formation generated in the fluid at the fitting. In the case of long pipelines of several kilometres, these local losses may be negligible, but for short pipelines they may be greater than the straight pipe frictional losses (Chadwick \& Morfett, 1993). A general theoretical treatment for local head losses is not available, but it is usual to assume rough turbulence (where the friction factor is independent of the Reynolds number) since it leads to a simple equation (Chadwick \& Morfett, 1993). The prediction of losses in pipe fittings is either based on (King, 2002):

a. The fitting will contribute to the energy dissipation an amount equivalent to an additional length of pipe that is calculated as a multiple of the pipe diameter.

b. The kinetic energy is dissipated as the fluid flows through the fitting and the loss is calculated in terms of the number of velocity heads that are lost.

Here, the losses in pipe fittings will be expressed as the number of velocity heads lost.

On dimensional grounds, the head loss in a fitting will depend upon the fluid velocity, fluid properties and the geometry of the fitting as follows (Edwards et al., 1985):

$$
\frac{2 \mathrm{gh}_{\text {fitt }}}{\mathrm{V}^{2}}=\mathrm{fn}(\text { Reynolds number, geometry })
$$

This can be expressed as a function of the velocity energy head given by

$$
\mathrm{h}_{\text {fitt }}=\mathrm{k}_{\text {fitt }} \frac{\mathrm{V}^{2}}{2 g}
$$

where $\mathrm{h}_{\text {fitt }}$ is the local head loss and $\mathrm{k}_{\mathrm{fitt}}$ is the fitting loss coefficient.

Since the pressure drop across the fitting, $\Delta \mathrm{p}_{\text {fitt }}$ is given by $\Delta \mathrm{p}_{\text {fitt }}=\rho g \mathrm{fh}_{\mathrm{fitt}}$, Eqn. (24) can be rewritten as

$$
\mathrm{k}_{\mathrm{fitt}}=\frac{\Delta \mathrm{p}_{\mathrm{fitt}}}{\frac{1}{2} \rho \mathrm{V}^{2}}
$$

The loss coefficient, $\mathrm{k}_{\mathrm{fitt}}$ is the non-dimensionalised difference in overall pressure between the ends of two long straight pipes when there is no fitting and when the real fitting is 
installed (Miller, 1978). The flow lengths over which pressure losses occur start from a few diameters upstream to several pipe diameters downstream of the actual length of the fitting. This is known as the region of influence or interference (see Figure 11). The pressure loss across the fitting $\Delta \mathrm{p}_{\text {fitt }}$ should be measured across this region. It can be the measured static pressure drop $\left(\Delta \mathrm{p}_{\mathrm{s}}\right)$ or the total pressure that is $\Delta \mathrm{p}_{\mathrm{tot}}=\Delta \mathrm{p}_{\mathrm{s}}+1 / 2 \rho \mathrm{V}^{2}$. It is therefore important to state whether $\mathrm{k}_{\mathrm{fitt}}$ is based on the static or total pressure (Miller, 1978). If there is a change in pipe diameter, the convention is to use the higher mean flow velocity (V) of either the upstream or the downstream pipe.

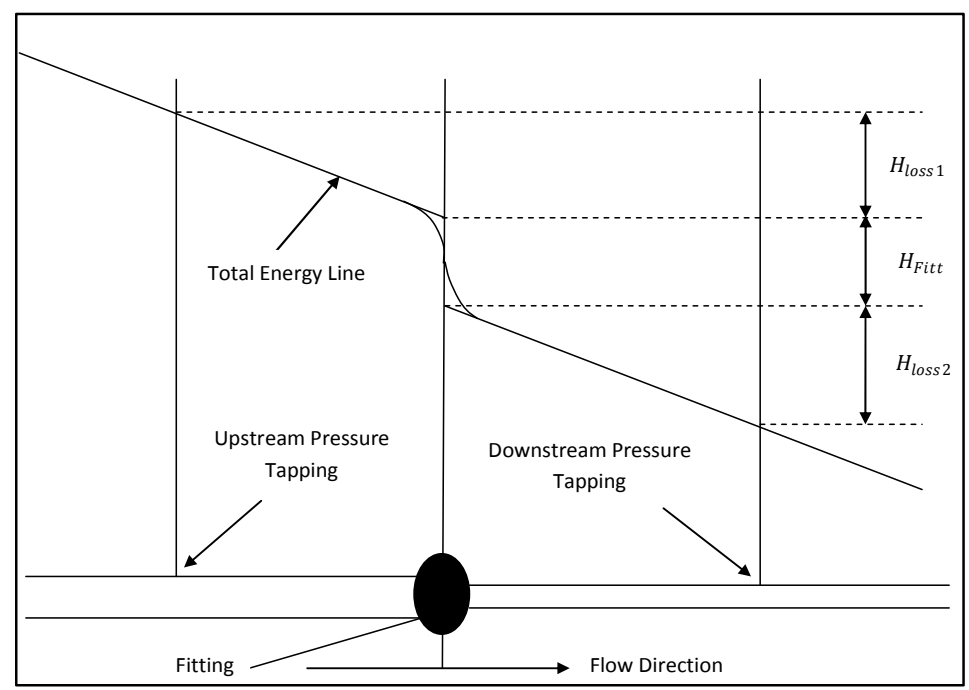

Fig. 11. Definition of energy head loss

With the exception of abrupt contractions and expansions, all other fittings have a physical length. There are three distinct conventions for estimating the length of the straight pipe in the test section (Perry \& Chilton, 1973):

i. the actual length of the centreline of the entire system is taken;

ii. the lengths of the individual pieces of pipe that are actually straight are summed up;

iii. the distances between the intersections of the extended centrelines of the successive straight pipes are added.

\subsection{Turbulent flow loss coefficient}

For turbulent flow through fittings, with the exception of bends, the loss coefficient is independent of the Reynolds number because inertia forces dominate. Experimental work showed that this is true for Newtonian fluids (Miller, 1978, Crane, 1999) and non-Newtonian fluids (Edwards et al., 1985, Ma 1987, Turian et al., 1998).

\subsection{Laminar flow loss coefficient}

For laminar flow, the loss coefficient is inversely proportional to the Reynolds number (Hooper, 1981; Edwards et al., 1985; Ma, 1987; Pienaar, 1998) and the data loci is presented 
as a straight line of slope $x=-1$ in most cases when tests are conducted to sufficiently low Reynolds numbers, i.e. $\operatorname{Re}<10$.

$$
\mathrm{k}_{\text {fitt }}=\frac{\mathrm{K}_{1}}{\operatorname{Re}^{\mathrm{x}}}
$$

where $K_{1}$ is the laminar flow loss coefficient constant and is a characteristic of a specific fitting involving its dimensions.

\subsection{Generalised correlation for loss coefficient}

Hooper (1981) provided a generalised correlation for the determination of the loss coefficient spanning Reynolds number from laminar to turbulent flow

$$
\mathrm{k}_{\mathrm{fitt}}=\frac{\mathrm{K}_{1}}{\mathrm{Re}}+\mathrm{k}_{\mathrm{turb}}\left(1+\frac{1}{\mathrm{D}_{\mathrm{i}}}\right)
$$

where $K_{1}$ and $k_{\text {turb }}$ are determined experimentally and $D_{i}$ is the pipe diameter in inches (King, 2002).

\subsection{Determination of loss coefficients}

The energy losses across a fluid-conveying conduit in a fluid are normally accounted for using the mechanical energy balance:

$$
\mathrm{z}_{1}+\frac{\alpha_{1} \mathrm{~V}_{1}^{2}}{2 \mathrm{~g}}+\frac{\mathrm{p}_{1}}{\rho \mathrm{g}}=\mathrm{z}_{2}+\frac{\alpha_{2} \mathrm{~V}_{2}^{2}}{2 \mathrm{~g}}+\frac{\mathrm{p}_{2}}{\rho \mathrm{g}}+\sum_{\mathrm{i}=1}^{\mathrm{N}} \mathrm{h}_{\text {loss }}
$$

where subscripts 1 and 2 refer to the upstream and downstream conditions respectively, $V$ is the mean flow velocity, $\mathrm{z}$ is the elevation from the datum, $\mathrm{a}$ is the kinetic energy correction factor and $\mathrm{p}$ is the static pressure and where there are $\mathrm{N}$ sources of energy loss (Edwards et al., 1985). Each term in the expression represents energy per unit weight of fluid, known as energy head or head loss, and is a statement of the law of conservation of energy as applied to fluid flow. The head loss is in units of metres. For the case of a head loss in a fitting, the energy equation may be rewritten as:

$$
\mathrm{z}_{1}+\frac{\alpha_{1} \mathrm{~V}_{1}^{2}}{2 \mathrm{~g}}+\frac{\mathrm{p}_{1}}{\rho \mathrm{g}}=\mathrm{z}_{2}+\frac{\alpha_{2} \mathrm{~V}_{2}^{2}}{2 \mathrm{~g}}+\frac{\mathrm{p}_{2}}{\rho \mathrm{g}}+\mathrm{h}_{1}+\mathrm{h}_{\text {fitt }}+\mathrm{h}_{2}
$$

where $h_{1}$ and $h_{2}$ refer to the friction head loss in the straight pipe upstream and downstream of the fitting and $h_{\text {fitt }}$ refers to the head loss in the fitting. The head loss, $h$, in the straight pipe can be calculated from

$$
\Delta \mathrm{h}=\frac{4 \mathrm{fL}}{\mathrm{D}}\left[\frac{\mathrm{V}^{2}}{2 \mathrm{~g}}\right]
$$

In practice, it is difficult to measure the pressure drop across the fitting only (Ward Smith, 1976) to distinguish between the incompletely developed and the fully-developed flow 
region prior to and after the fitting. One method is to extrapolate the fully developed pressure gradient to the fitting centreline if the pressure is measured along the length of the two pipes. The second method is to measure the total pressure drop across the system by using two pressure taps only. The latter is experimentally a cheaper method, as only one pressure transducer is required. There are difficulties associated with both methods that could influence the results obtained to some extent. For the pressure gradient to be determined, it is required to select the points that are in the fully developed friction gradient region, but this is not always an easy task, as the distance of interference changes with Reynolds number (Pal \& Hwang, 1999). For the total pressure drop method on the other hand, one needs to ensure that the additional losses are accounted for by ensuring that there is significant length of straight pipe. The difficulty is often encountered that to determine the loss in the fitting, two large numbers are being subtracted to obtain a very small number, resulting in significant errors or negative results (Sisavath, 2002). The following was found when data obtained for Newtonian lubrication oil flowing through sudden contractions was analysed using the pressure grade line approach as well as the total pressure drop approach to obtain values of $\mathrm{k}_{\text {turb }}$ and $\mathrm{K}_{1 \text { con }}$ and compared to results found in literature as shown in Figure 12.

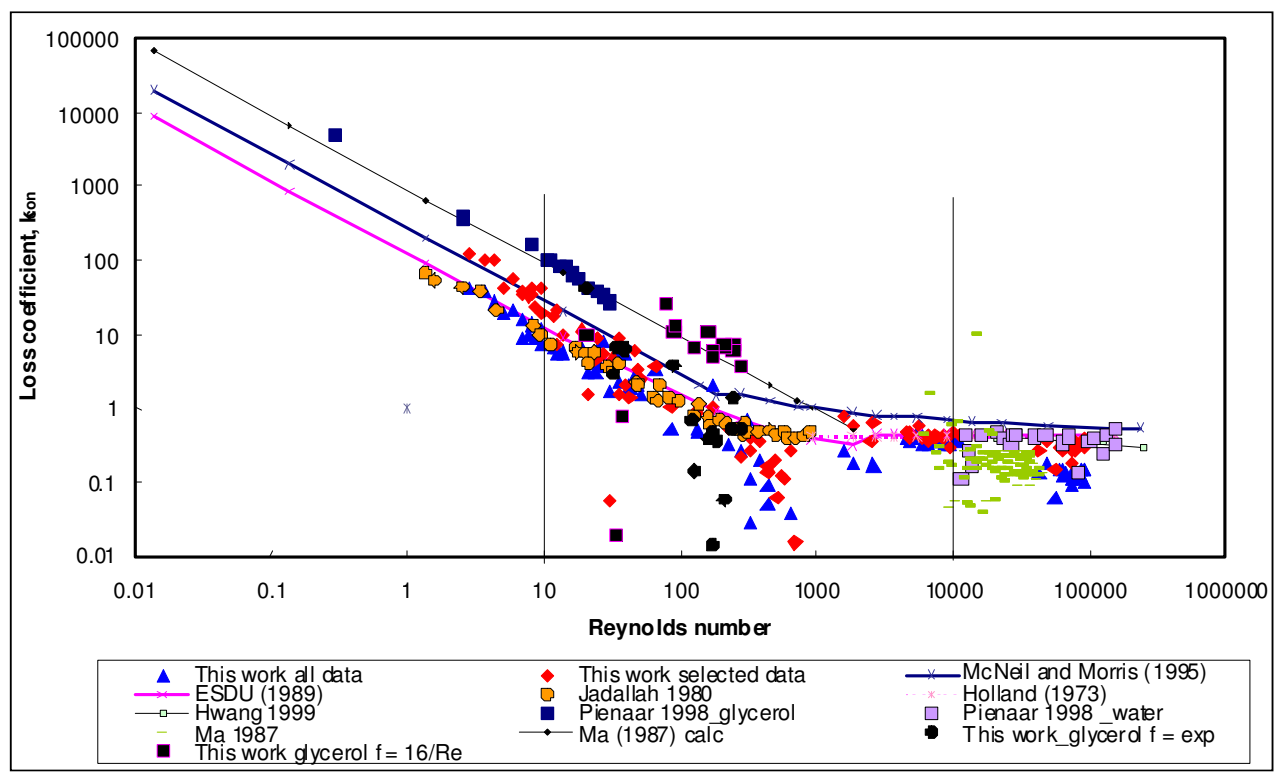

Fig. 12. Comparison of different analysis method to determine loss coefficient (Pienaar \& Slatter, 2004)

Between $\operatorname{Re}=10-10$ 000, the fact that all the data points are used for extrapolation or that some data are selected gives little difference in the loss coefficient calculated. It is clear that the range of data selected for analysis of results has a significant effect at Reynolds numbers less than 10 and greater than 10 000. Good agreement was found between this work using all data and that of Jadallah (1980) and the prediction of ESDU (1989). 
- At $\operatorname{Re}>10$ 000, the results were significantly lower than predicted results and it was obvious that in this range the data closed to the contraction plane had to be excluded from the pressure gradient analysis.

- At $\operatorname{Re}<10$, good agreement was found between this work using selected data and the prediction of McNeil and Morris (1995).

- Discrepancies between $K_{1}$ values are often due to the fact that results are not obtained at Reynolds numbers less than 10 in the purely viscous range before onset of turbulence.

It is evident that it is not only the physical experimental measurements that contribute to the large scatter of results, but also the analytical approach applied to the experimental results to obtain loss coefficients. It is important to analyse experimental results in various ways by assessing experimental data very carefully.

\subsection{Dynamic similarity}

Complete analytical solutions for engineering problems involving the flow of real fluids is seldom attainable and experiments on models of different physical size are often a necessary part of the design process. This investigation is typical of this approach. In order to correctly interpret the qualitative and quantitative data obtained from such experiments, it is necessary to understand the relationship between models of different size. The concepts of dimensional analysis and physical, geometric, kinematic and dynamic similarity are introduced as they apply to the specific problem of modelling and data interpretation of fittings of different size. Dimensional analysis enables the magnitudes of individual quantities relevant to a physical problem to be assembled into dimensionless groups, often referred to by name. The dimensionless group of specific interest here is the Reynolds number. These groups assist in the interpretation of model studies by ensuring that the conditions under which tests and observations take place at one size fitting are the same as those at the other size fitting.

Physical similarity, like dimensional analysis, helps to ensure that the conditions under which tests and observations take place at one scale are the same as those on another scale. The models at different scale are said to be physically similar in respect of specified physical quantities (eg, velocity), when the ratio of corresponding magnitudes of these quantities between the two systems are everywhere the same. For any comparison between models, the sets of conditions associated with each must be physically similar.

Geometric similarity is similarity of shape. The requirement is that any ratio of length in one model to the corresponding length in another model is everywhere the same. This ratio is referred to as the scale factor. Geometric similarity is the first requirement of physical similarity. Kinematic similarity is similarity of motion and requires similarity of both length and time interval.

Dynamic similarity is similarity of forces. Since there may be several kinds of forces acting on a fluid particle, it is usually impossible to satisfy dynamic similarity for all of them simultaneously. The justification for comparing observations from one model flow system to another is that the fluid behaviour in both systems is similar thus implying kinematic similarity. Geometric similarity alone does not imply dynamic similarity. The requirement for kinematic similarity is to have both geometric and dynamic similarity. This produces geometric similarity of flow patterns and it is this which is of prime importance in this study. 
It was shown by Edwards et al. (1985) and Fester and Slatter (2009) that if geometric similarity is maintained, the Reynolds number can be used to establish dynamic similarity in globe and gate valves. Although Edwards et al. (1985) initially indicated that for turbulent flow in globe valves, the turbulent loss coefficient is geometry dependent, this was later found to be due to the globe valves not being geometrically similar. Fester and Slatter (2009) found that the turbulent loss coefficient is in fact independent of the valve size for the geometrically similar globe valves tested. This was found to be in agreement with Edwards et al.'s (1985) findings for gate valves. It will only depend on the valve opening for carefully machined valves. However, results for diaphragm valves agreed with Edwards et al.'s statement that for significant changes in cross-sectional areas, the result becomes size dependent. The viscous force dominated range at $\operatorname{Re}<10$ is not affected by valve size. In fact, the $\mathrm{K}_{1}$ value obtained for non-Newtonian fluids is in excellent agreement with that provided by Hooper (1981). As the Reynolds number increases beyond the critical Reynolds number as inertia forces begin to dominate, the loss coefficient is sensitive to geometry and valve size. Results for valves from different manufacturers are remarkably different in this region and this is directly related to the flow path. Furthermore, the valves were rubberlined, and this influenced the actual final diameter of the valve.

\subsection{Transition from laminar to turbulent flow}

Miller (1978) presented general idealized curves of the laminar to turbulent transition region as shown in Figure 13. The transition is not always sharp since it can be the entire region from where the loss coefficient starts to deviate from the trend of being inversely proportional to the Reynolds number to where it becomes independent of the Reynolds number. Sometimes a minimum is reached before the loss coefficient increases and then takes a constant value in turbulent flows. The transition region starts where the flow upstream of the fitting is laminar, but downstream turbulence is introduced (Jameson \& Villemonte, 1971). Since the Stokes flow region is between $1<\operatorname{Re}<10$, it is important that tests must be conducted in this range to ascertain the onset of transitional flow. Various

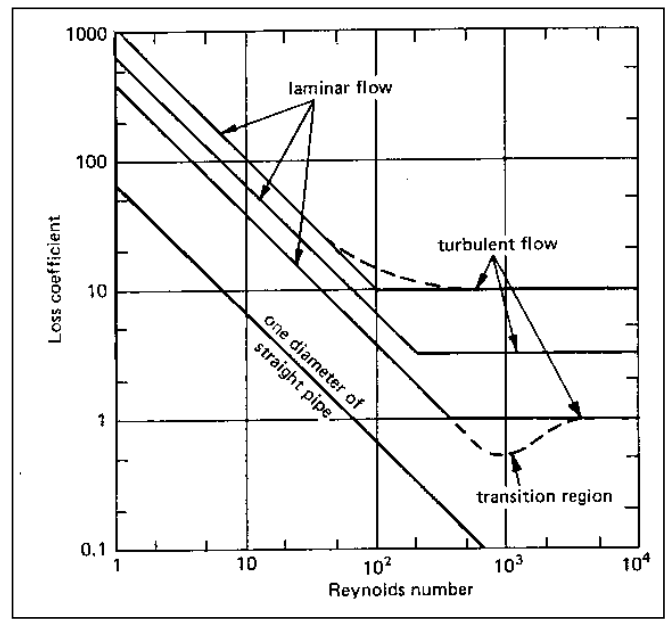

Fig. 13. Trends in loss coefficients in the laminar to turbulent transition region (Miller, 1978) 
conflicting transition Reynolds numbers that have been reported is mainly due to the different definitions used for onset of transitional flow. It has been defined as either the intersection between the straight lines for laminar flow and turbulent flow (Ma, 1987) or as the point where the data starts to deviate from the laminar flow line (Fester \& Slatter, 2009). The latter always occur at Reynolds numbers lower than that predicted by the intersection method. For short orifices, the ratio of the Reynolds number from the onset of deviation from laminar flow to that of fully developed turbulent flow was found to be $\approx 0.008$ for $\beta$ ratios ranging from 0.2 to 0.7 . For sudden contractions and long orifices, this minimum value is not as pronounced as for short orifices as shown in Figures 14 to 16.

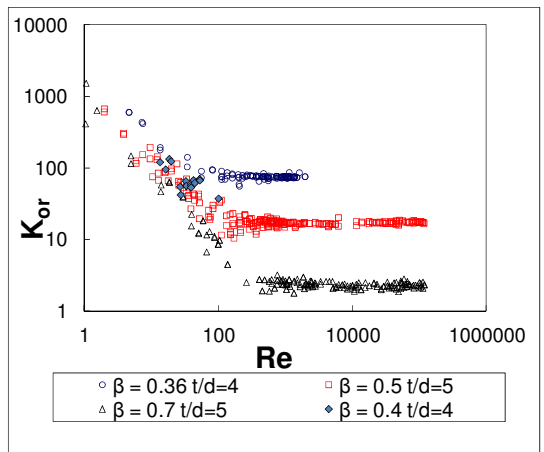

Fig. 14. Data showing transition region for a long orifice (Fester et al., 2010)

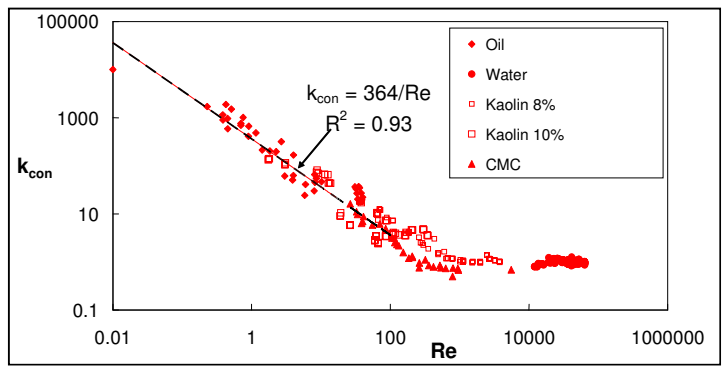

Fig. 15. Data showing transition region for a sudden contraction (Fester et al., 2008)

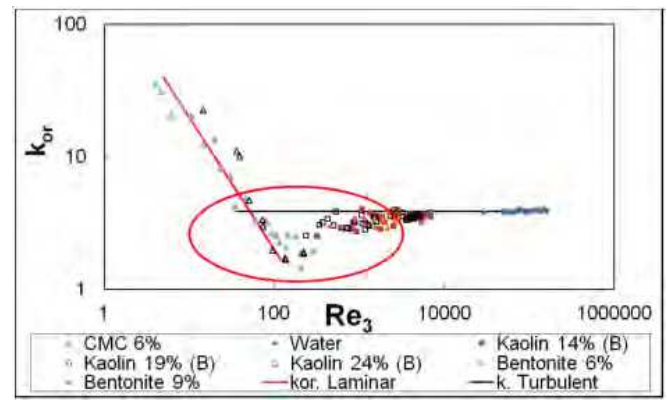

Fig. 16. Data showing transition region for a short orifice (Ntamba, 2011) 


\subsection{Loss coefficient data}

Loss coefficients for both laminar and turbulent flow of Newtonian and non-Newtonian fluids through various types of fittings are provided for engineering design calculations.

\subsubsection{Contractions and expansions}

For sudden contractions and expansions where $\beta$ is the ratio of the downstream $\left(d_{d}\right)$ to upstream $\left(\mathrm{d}_{\mathrm{u}}\right)$ pipe diameter, $\mathrm{K}_{1}$ values for non-Newtonian fluids were found to be similar to those found for Newtonian fluids. Here, the non-Newtonian behaviour of the fluid was accounted for by using the appropriate Reynolds number for the fluid. This was the conclusion drawn by Edwards et al.(1985), Ma (1987), Pienaar (1998), Pal and Hwang (1999) and Fester et al. (2008). Mika (2011) was, however, unable to establish dynamic similarity for laminar flow of ice slurries of various concentrations in sudden contractions. Tables 1 and 2 show a comparison of the results obtained by various workers for sudden contractions and expansions respectively. In general, there was much better agreement between values in turbulent flow than those in laminar flow for which no quantitative agreement was found amongst the work of different researchers or correlations to predict losses through sharpedged contractions and expansions.

\begin{tabular}{|l|l|c|c|c|}
\hline \multicolumn{1}{|c|}{ STUDY } & \multicolumn{1}{c|}{ Fluid } & $\boldsymbol{\beta}_{\text {con }}$ & $\mathbf{K}_{\mathbf{1} \text { con }}$ & $\mathbf{k}_{\text {con }}$ \\
\hline Hooper, 1981 & - & - & 160 & - \\
\hline Edwards et al., 1985 & $\begin{array}{l}\text { 50\% glycerol/water } \\
\text { Lubricating oil }\end{array}$ & 0.445 & 110 & 0.45 \\
\hline Edwards et al., 1985 & $\begin{array}{l}\text { 50\% glycerol/water } \\
\text { Lubricating oil, CMC, China clay }\end{array}$ & 0.660 & 59 & 0.33 \\
\hline Ma, 1987 & Laterite \& Gypsum slurries & 0.5 & 900 & 0.23 \\
\hline Pienaar, 1998 & 100\% Glycerol, Kaolin, CMC & 0.463 & 640 & 0.414 \\
\hline Pienaar, 1998 & 100\% Glycerol, Kaolin, CMC & 0.204 & 1300 & 0.44 \\
\hline Pal \& Hwang, 1999 & Oil-in-water Emulsions & 0.49 & - & 0.43 \\
\hline
\end{tabular}

Table 1. Loss coefficient data for sudden contractions

\begin{tabular}{|l|l|c|c|c|}
\hline \multicolumn{1}{|c|}{ Reference } & \multicolumn{1}{c|}{ Fluid } & $\boldsymbol{\beta}_{\exp }$ & $\mathbf{K}_{\mathbf{1 e x p}}$ & $\mathbf{k}_{\exp }$ \\
\hline Idelchik, 1966 & Newtonian fluids & - & 30 & - \\
\hline Edwards et al., 1985 & Glycerol, CMC Solutions, China clay & 1.97 & 139 & 0.55 \\
\hline Edwards et al., 1985 & Glycerol, CMC Solutions, China clay & 1.52 & 87.7 & 0.32 \\
\hline Edwards et al., 1985 & Glycerol, CMC Solutions, China clay & 2.18 & 150 & 0.62 \\
\hline Ma, 1987 & Laterite, Gypsum & 2 & 115 & 0.551 \\
\hline Pienaar, 1998 & Water, Glycerol, Kaolin, CMC & 2.16 & 959 & 0.954 \\
\hline Pienaar, 1998 & Water,Glycerol,Kaolin, CMC & 4.9 & 1408 & 0.918 \\
\hline Turian et al., 1998 & Laterite, Gypsum & 2 & - & 0.551 \\
\hline Pal \& Hwang, 1999 & Oil-in-water emulsions & 0.49 & - & 0.49 \\
\hline
\end{tabular}

Table 2. Loss coefficient data for sudden expansions 


\subsubsection{Valves}

Valves form an integral part of slurry pipework systems. These fall within the category of fittings that influence slurry flow in pipework by opening, closing, diverting, mixing or partially obstructing the flow passage (Whitehouse, 1993). An isolation (on-off) valve is a valve designed for use in either the fully open or closed position. Those suitable for slurry service include knife gate, parallel gate, diaphragm, pinch, plug, ball, butterfly and rotating disc (Alderman \& Heywood, 1996).

A regulating (throttling) valve is a valve designed for use in all positions between fully open and fully closed. Those suitable for slurry service include globe, diaphragm, pinch and segmented ball (Alderman \& Heywood, 1996). Work on frictional pressure losses arising from flow through valves has been carried out with Newtonian slurries using both isolation and regulating valves. Initially, work with non-settling, non-Newtonian slurries appears to have been restricted to gate and globe valves (Edwards et al., 1985; Turian et al., 1998; Pal \& Hwang, 1999). This work was extended to diaphragm valves by Mbiya et al. (2009) and Kabwe et al. (2010).

\subsubsection{Globe and gate valves}

A summary of loss coefficient data for gate and globe valves are provided in Table 3 ranging from $12.5 \mathrm{~mm}$ to $40 \mathrm{~mm}$. Figure 17 shows experimental data obtained for 12.5, 25, 40 and 65 $\mathrm{mm}$ globe valves from two different manufacturers. A range of Newtonian and nonNewtonian fluids were tested for Reynolds numbers covering from 0.05 to 1000000 obtained from three different test rigs (Fester \& Slatter, 2009). In laminar flow, good agreement was obtained with those obtained by Hooper for a standard globe valve, but in turbulent flow, the predicted values for a 1 inch globe valve approximated those for the $65 \mathrm{~mm}$ valve. The laminar to turbulent transition for the $12.5,25$ and $40 \mathrm{~mm}$ valves was found to be smooth whereas a minimum was obtained for the $65 \mathrm{~mm}$ valve.

\begin{tabular}{|l|l|c|c|c|c|}
\hline \multicolumn{1}{|c|}{ Type } & \multicolumn{1}{c|}{ Fluid } & Setting & K1valve & x & $\mathbf{k}_{\text {valve }}$ \\
\hline $\begin{array}{l}\text { Gate: } \\
\text { Hooper, } 1981\end{array}$ & Newtonian & Full open & 300 & 1 & 0.1 \\
\hline $\begin{array}{l}\text { Globe Standard: } \\
\text { Hooper, } 1981\end{array}$ & Newtonian & Full open & 1500 & 1 & 4 \\
\hline $\begin{array}{l}\text { Globe Angle/Y: } \\
\text { Hooper, } 1981\end{array}$ & Newtonian & Full open & 1000 & 1 & 2 \\
\hline $\begin{array}{l}\text { Gate: } 1 \text { inch } \\
\text { Turian et al., } 1998\end{array}$ & $\begin{array}{l}\text { Laterite and } \\
\text { Gypsum slurries }\end{array}$ & Full open & 320 & 1 & 0.80 \\
\hline $\begin{array}{l}\text { Gate: } 2 \text { inch } \\
\text { Turian et al., } 1998\end{array}$ & $\begin{array}{l}\text { Laterite and } \\
\text { Gypsum slurries }\end{array}$ & Full open & 320 & 1 & 0.17 \\
\hline $\begin{array}{l}\text { Gate: } 1 \text { inch Edwards } \\
\text { et al., } 1985\end{array}$ & $\begin{array}{l}\text { CMC solutions } \\
\text { China clay slurries }\end{array}$ & Full open & 273 & 1 & - \\
\hline $\begin{array}{l}\text { Gate: } 2 \text { inch Edwards } \\
\text { et al., } 1985\end{array}$ & $\begin{array}{l}\text { CMC solutions } \\
\text { China clay slurries }\end{array}$ & Full open & 273 & 1 & - \\
\hline $\begin{array}{l}\text { Globe: } 1 \text { inch } \\
\text { Edwards et al., } 1985\end{array}$ & $\begin{array}{l}\text { CMC solutions } \\
\text { China clay slurries }\end{array}$ & Full open & 1460 & 1 & 122 \\
\hline
\end{tabular}




\begin{tabular}{|l|l|c|c|c|c|}
\hline \multicolumn{1}{|c|}{ Type } & \multicolumn{1}{c|}{ Fluid } & Setting & K $_{\text {1valve }}$ & x & $\mathbf{k}_{\text {valve }}$ \\
\hline $\begin{array}{l}\text { Globe: } 2 \text { inch } \\
\text { Edwards et al., 1985 }\end{array}$ & $\begin{array}{l}\text { CMC Solutions } \\
\text { China clay slurries }\end{array}$ & Full open & 384 & 1 & 25.4 \\
\hline $\begin{array}{l}\text { Globe: } 1 \text { inch } \\
\text { Pal \& Hwang, 1999 }\end{array}$ & $\begin{array}{l}\text { Oil-in-water } \\
\text { emulsions }\end{array}$ & Full open & 62 & 0.53 & - \\
\hline $\begin{array}{l}\text { Globe: } 1 \text { inch } \\
\text { Pal \& Hwang, } 1999\end{array}$ & $\begin{array}{l}\text { Oil-in-water } \\
\text { emulsions }\end{array}$ & Half open & 169 & 0.53 & - \\
\hline $\begin{array}{l}\text { Globe: } 1 \text { inch } \\
\text { Turian et al., } 1998\end{array}$ & $\begin{array}{l}\text { Laterite and } \\
\text { Gypsum slurries }\end{array}$ & Full open & - & - & 10.0 \\
\hline $\begin{array}{l}\text { Globe: } 25,15,40 \mathrm{~mm} \\
\text { Fester et al, } 2009\end{array}$ & $\begin{array}{l}\text { Water, CMC, } \\
\text { Koalin slurries }\end{array}$ & Full open & 700 & 1 & 12 \\
\hline $\begin{array}{l}\text { Globe:, 25, 15, } 40 \mathrm{~mm} \\
\text { Fester et al, } 2009\end{array}$ & $\begin{array}{l}\text { Water, CMC, } \\
\text { Koalin slurries }\end{array}$ & Half open & 1200 & 1 & 23 \\
\hline
\end{tabular}

Table 3. Loss coefficient data for globe and gate valves

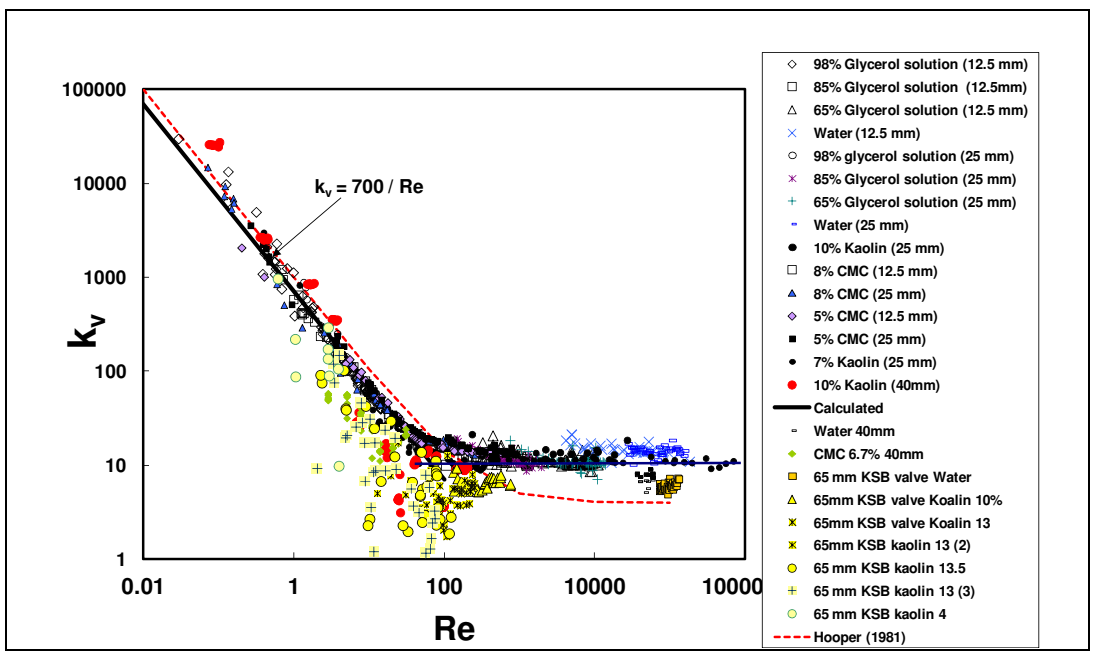

Fig. 17. Comparison of experimental pressure loss coefficient with various correlations (Fester \& Slatter, 2009)

\subsubsection{Diaphragm valves}

Extensive experimental work was conducted on straight-through diaphragm valves from two manufacturers (Kabwe et al., 2010). The nominal valve sizes were 40, 50, 65, 80 and 100 $\mathrm{mm}$. The fluids tested were water, carboxymethyl cellulose solutions and kaolin suspensions. It was observed that at Reynolds numbers below 10, the loss coefficient is independent of the valve opening for valves from both manufacturers. This purely laminar

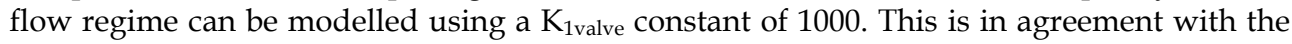
value provided by Hooper (1981). However, in the fully turbulent regime this loss coefficient for the Natco valves were found to be higher than those for Saunders valves. This may be attributed to the more tortuous flow path of the Natco valve compared with that of 
the Saunders valve. A new correlation was developed to account for the prediction of head losses through diaphragm valves at various opening positions that would be useful for design purposes. This is given by

$$
\mathrm{k}_{\mathrm{valve}}=\frac{1000}{\operatorname{Re}}+\frac{\lambda_{\Omega}}{\theta^{2.5}}
$$

where $\lambda_{\Omega}$ is $\mathrm{k}_{\text {valve }}$ at $100 \%$ opening and $\theta$ is the valve opening. The results obtained for the valves are given in Table 4 .

\subsubsection{Orifices}

Loss coefficient data for orifices are provided in Table 5 and 6. Johansen, in 1930, initiated the first detailed studies on sharp edged concentric orifices but as recent as 2007 the lack of pressure loss coefficient data for $\beta$ ratios of $0.2,0.3,0.4,0.5$ and 0.7 in literature for long and short orifices was identified (ESDU, 2007). Little work has been done with non-Newtonian fluid despite their importance in the field of polymer processing, flow of petroleum products, biomedical engineering, biochemical engineering, food processing, and mineral processing plants. In such applications, the flow remains laminar even at large flow rates (Bohra , 2004). Correlations found in literature are generally for turbulent flow regimes for which the loss coefficients mainly depends on the geometry of the orifice, practically independent of Reynolds number.

\begin{tabular}{|l|c|c|c|c|c|}
\hline \multicolumn{1}{|c|}{ TYPE } & \multirow{2}{*}{$\begin{array}{c}\text { size } \\
(\mathbf{m m})\end{array}$} & \multicolumn{5}{c|}{$\mathbf{k}_{\text {valve }}$ at opening } \\
\cline { 3 - 6 } & 100 & 69 & 18 & 4.7 & 1.0 \\
\hline $\begin{array}{l}\text { Saunders Diaphragm valve } \\
\text { Kabwe et al., 2010 }\end{array}$ & 80 & 28 & 19 & 4.3 & 0.5 \\
\hline $\begin{array}{l}\text { Saunders Diaphragm valve } \\
\text { Kabwe et al., 2010 }\end{array}$ & 65 & 22 & 3.6 & 1.8 & 0.6 \\
\hline $\begin{array}{l}\text { Saunders Diaphragm valve } \\
\text { Kabwe et al., 2010 }\end{array}$ & 50 & 89 & 10 & 3.9 & 1.6 \\
\hline $\begin{array}{l}\text { Saunders Diaphragm valve } \\
\text { Kabwe et al., 2010 }\end{array}$ & 40 & 72 & 33 & 8.2 & 2.7 \\
\hline $\begin{array}{l}\text { Saunders Diaphragm valve } \\
\text { Kabwe et al., 2010 }\end{array}$ & 100 & 100 & 29 & 10 & 1.4 \\
\hline $\begin{array}{l}\text { Natco Diaphragm valve } \\
\text { Mbiya et al., 2009 }\end{array}$ & 80 & 67 & 18 & 6.8 & 2.5 \\
\hline $\begin{array}{l}\text { Natco Diaphragm valve } \\
\text { Mbiya et al., 2009 }\end{array}$ & 65 & 63 & 16 & 2.8 & 1.2 \\
\hline $\begin{array}{l}\text { Natco Diaphragm valve } \\
\text { Mbiya et al., 2009 }\end{array}$ & 50 & 85 & 25 & 8.1 & 2.5 \\
\hline $\begin{array}{l}\text { Natco Diaphragm valve } \\
\text { Mbiya et al., 2009 }\end{array}$ & 40 & 211 & 35 & 18 & 8.1 \\
\hline $\begin{array}{l}\text { Natco Diaphragm valve } \\
\text { Mbiya et al., 2009 }\end{array}$ & & & & \\
\hline
\end{tabular}

Table 4. Loss coefficient data for diaphragm valves 


\subsubsection{Long orifices}

In 1972, Lakshmana Rao and his co-workers obtained the pressure loss coefficients for laminar flow in five sharp square-edged long orifices with a constant $\beta$ ratio of 0.2 whilst varying the thickness to diameter ratios from 0.48 to 10.11 . Pressure loss coefficients in turbulent flow for orifices with $\beta$ ratios of $0.36,0.4,0.5$ and 0.7 with aspect ratios of $4,4,5$ and 5 respectively are compared with those of Ward-Smith (1971) and Idel'chik et al. (1994). Excellent agreement was found between experimental work and turbulent flow correlations from Ward-Smith (1971) and Idel'chik et al. (1994), with maximum difference between the experimental data models were $9.87 \%$ and $12 \%$ respectively for the maximum beta ratio of 0.7. This difference was well within the experimental error obtained. The comparison shows clearly that correlations published by Ward-Smith (1971) and Idel'chik et al. (1994) can be used from $\operatorname{Re}>1000$, although the two models has an applicability range from $\operatorname{Re}>10^{4}$.

Due to lack of correlations to predict losses through long orifices for laminar flow, the correlations of Hasegawa et al. (1997) and Bohra (2004), although limited to $\beta=0.1$ and 0.137 respectively, were evaluated at the higher orifice diameter ratios tested in this work. Hasegawa et al. (1997) shows good agreement in laminar flow for the Stokes flow region, Re $<10$, for $\beta=0.5$. It is however unable to predict turbulent flow. Bohra (2004) approximates turbulent flow data very well for all cases except for $\beta=0.7$. However, there is good agreement in laminar flow for $\beta=0.7$. The comparison (Figure 18) also revealed that an improvement of the models is required to predict losses accurately over a wide range of laminar and turbulent flow. No suitable correlation was found in the literature to predict pressure losses through long square edged orifices from laminar to turbulent flow regimes. The loss coefficient data obtained from the experimental work (Fester et al., 2010) is given in Table 5.

\begin{tabular}{|c|c|c|c|c|c|}
\hline STUDY & FLUID & $\boldsymbol{\beta}_{\text {Lor }}$ & $\mathbf{t} / \mathbf{d}$ & $\mathbf{K}_{\text {1Lor }}$ & $\mathbf{k}_{\text {Lor }}$ \\
\hline Fester et al., 2010 & CMC, Kaolin, & 0.36 & 4 & 3500 & 76 \\
\hline Fester et al., 2010 & CMC, Kaolin & 0.40 & 4 & 2100 & 44 \\
\hline Fester et al., 2010 & CMC, Kaolin & 0.50 & 5 & 1500 & 17 \\
\hline Fester et al., 2010 & CMC, Kaolin & 0.70 & 5 & 860 & 2.3 \\
\hline
\end{tabular}

Table 5. Loss coefficient data for long orifice

\subsubsection{Short orifices}

Although the work on orifices started in the early 1900s, it was mainly for determining discharge coefficients (Johansen, 1930; Medaugh \& Johnson, 1940). A comparison of pressure loss characteristics of different geometries orifices and nozzles was done by Alvi et al. (1978). They found that the flow characteristics of orifices can be divided into three regimes: fully laminar region, re-laminarising region and turbulent region. Lakshmana Rao et al. (1977) investigated the critical Reynolds number for orifice and nozzle flows and found that the critical Reynolds number approached a constant value for low value of orifice or nozzle diameter to pipe diameter ratio. The work done on flow through orifice plate was carried out using Newtonian fluids. In such applications, the flow remains laminar even at large flow rates (Bohra et al., 2004). Edwards et al. (1985) used aqueous solutions of carboxymethylcellulose and suspensions of china clay in water through orifice plates. 
Significant differences were found between the experimental results of Edwards et al. (1985) and those of Ntamba (2011) as shown in Table 6. However, the results of Ntamba (2011) shown in Figure 19 are in good agreement with that of Lakshmana Rao et al. (1977).

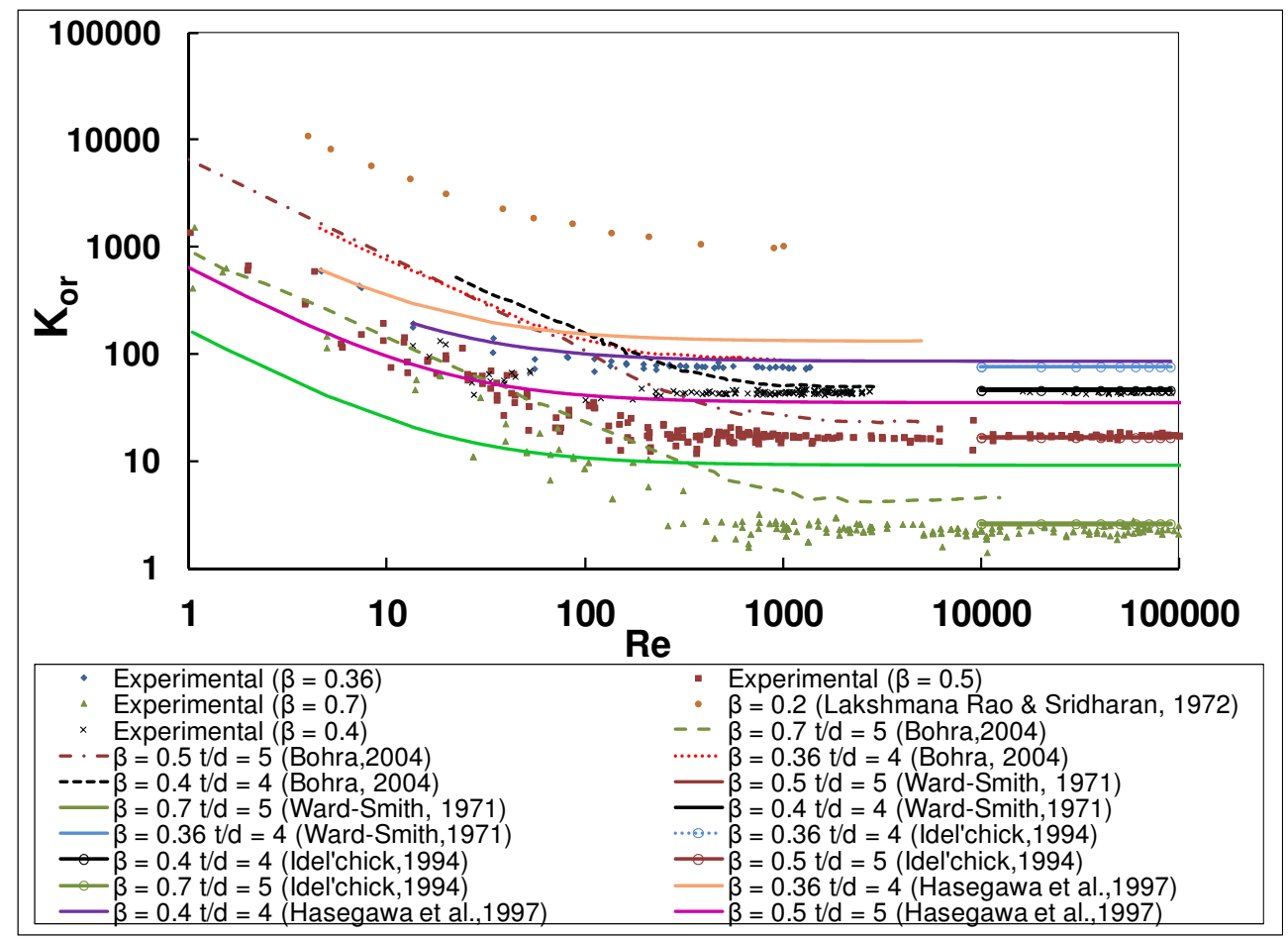

Fig. 18. Comparison of experimental pressure loss coefficient with correlations for long orifices

\begin{tabular}{|l|l|c|c|c|}
\hline \multicolumn{1}{|c|}{ STUDY } & \multicolumn{1}{|c|}{ FLUID } & $\boldsymbol{\beta}_{\text {or }}$ & $\mathbf{K}_{\text {1or }}$ & $\mathbf{k}_{\text {or }}$ \\
\hline Edwards et al., 1985 & $\begin{array}{l}\text { 50\% glycerol/water } \\
\text { Lubricating oil }\end{array}$ & 0.289 & 786 & - \\
\hline Edwards et al., 1985 & $\begin{array}{l}\text { 50\% glycerol/water } \\
\text { Lubricating oil, CMC, China clay }\end{array}$ & 0.577 & 154 & - \\
\hline Ntamba, 2011 & Koalin, CMC, Bentonite & 0.20 & 2250 & 1213 \\
\hline Ntamba, 2011 & Koalin, CMC, Bentonite & 0.30 & 1111 & 227 \\
\hline Ntamba, 2011 & Koalin, CMC, Bentonite & 0.57 & 340 & 14.2 \\
\hline Ntamba, 2011 & Koalin, CMC, Bentonite & 0.70 & 122 & 3.85 \\
\hline
\end{tabular}

Table 6. Loss coefficient data for short orifices 


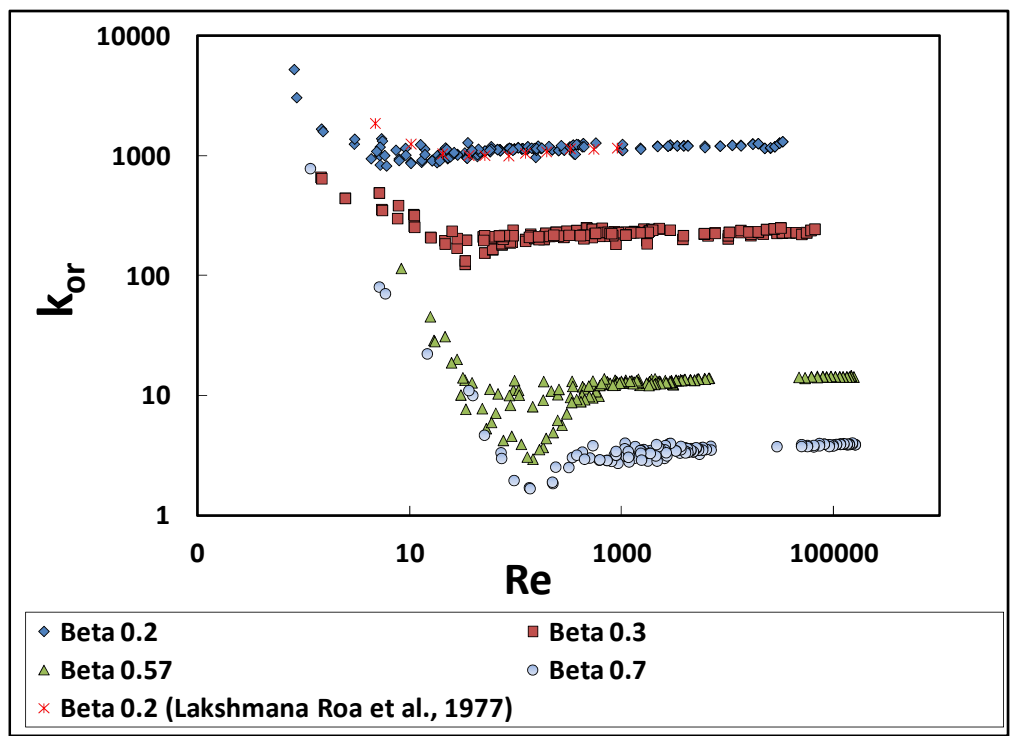

Fig. 19. Experimental pressure loss coefficient data for short orifices

\section{Worked example ${ }^{1}$}

In order to illustrate the effect that the fittings loss has in laminar viscoplastic flow, a simple system consisting of $10 \mathrm{~m}$ of straight $50 \mathrm{~mm}$ ID pipe and 5 fittings - the loss coefficient of the above diaphragm valve in laminar flow is $\mathrm{k}_{\mathrm{v}}=946 / \mathrm{Re}_{3}$, and for turbulent flow is constant at $\mathrm{k}_{\mathrm{v}}=2.5$ - is set and analysed. The fluid used for the analysis is a viscoplastic paste $\left(\tau_{\mathrm{y}}=100\right.$ $\mathrm{Pa}, \mathrm{K}=1$ Pa.s, relative density $=1.5$ and $\mathrm{n}=1$ ). These values were chosen so as to present a relatively simple viscoplastic rheology which would yield laminar flow in a $50 \mathrm{~mm}$ pipe at $3 \mathrm{~m} / \mathrm{s}$.

The objective of the analysis was to obtain the head loss as a function of volumetric flow rate. The operating flow rate considered was $0.006 \mathrm{~m}^{3} / \mathrm{s}$ which corresponded to an operating average velocity $\mathrm{V}$ of $3 \mathrm{~m} / \mathrm{s}$ in a $50 \mathrm{~mm}$ pipe.

Since the value of the laminar flow loss coefficient is not available to most designers, the effect of incorrectly using the turbulent - constant - value for design in laminar flow will be highlighted.

Figure 20 shows the fittings head losses in both laminar and turbulent flow. Figure 20 shows three principal differences between the fittings head losses in both laminar and turbulent flow:

1. The significant contribution of the laminar fittings loss to the start-up static head $($ at $Q=0)$.

2. The very different shape presentation between laminar and turbulent flow.

3. The significant difference in magnitude which arises.

${ }^{1}$ From Slatter \& Fester (2010): reproduced with permission 


\subsection{Start-up static head}

In this example, the contribution of the laminar fittings loss to the start-up static head (at $\mathrm{Q}=0$ ) is $6.5 \mathrm{~m}$, as can be seen on the ordinate of Figure 20. Inspection of Eqn. (24) might lead one to expect a zero result at $Q=0$, as portrayed by the turbulent locus in Figure 20.

However, it must be understood that this non-zero value is a result of the combined effects of Eqns. (13), (24) and (26), and is a sign of the presence of a yield stress.

\subsection{Shape presentation}

The inherently parabolic shape of the turbulent locus in Figure 20 is a direct consequence of the quadratic form of Eqn. (24) and the constant value of the loss coefficient $k_{\text {fitt }}=2.5$ for this valve type in turbulent flow.

Equally, the inherently viscoplastic shape of the laminar locus in Figure 20 is a direct consequence of the hyperbolic form of Eqn. (26) combined with the emphasis of the role of the yield stress in Eqn. (13).

\subsection{Difference in magnitude}

Figure 20 shows that there are considerable differences in the magnitude of the fittings Head losses in laminar and turbulent flow. A direct comparison of these magnitudes is shown in Figure 21.

Figure 21 shows that the difference in magnitude is best expressed in orders of magnitude.

In this example, the fittings head losses in laminar flow shown in Figure 20 and Figure 21 exceed those in turbulent flow by several orders of magnitude.

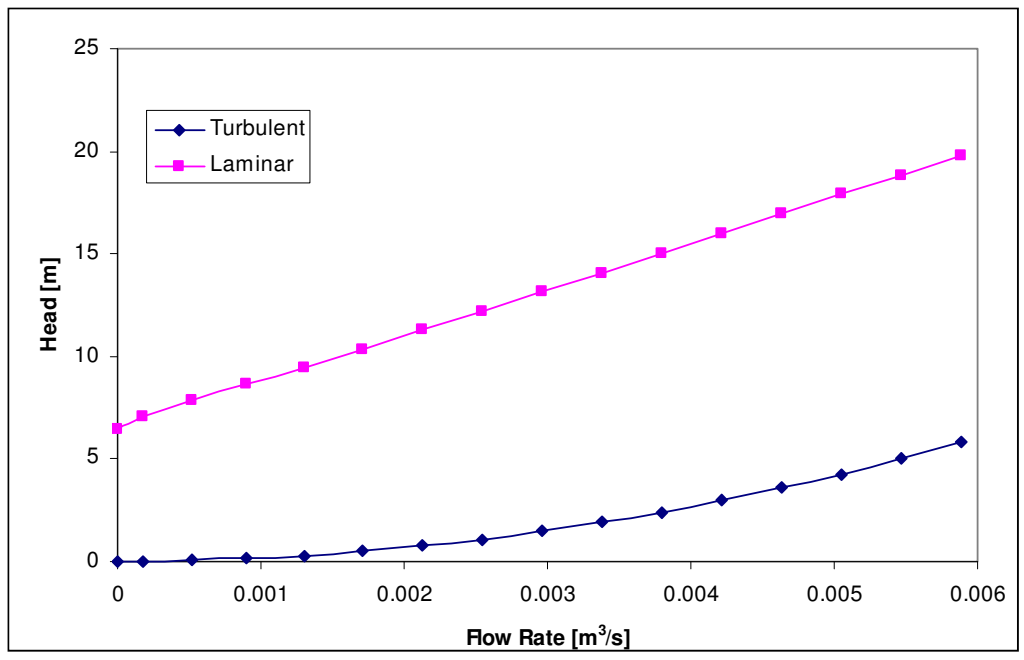

Fig. 20. Fittings Head Losses in Laminar and Turbulent flow 


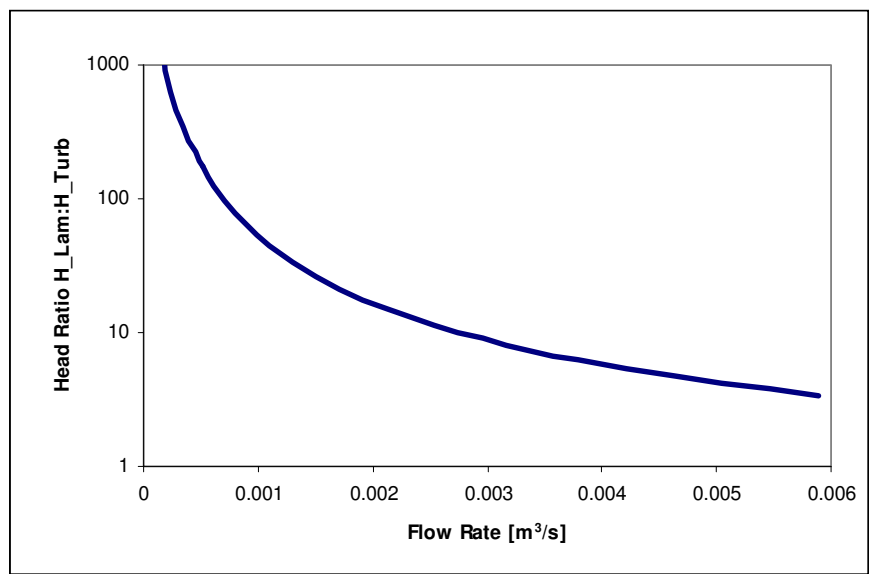

Fig. 21. Comparison of the Fittings Head Losses in Laminar and Turbulent flow shown in Figure 20

\subsection{Pump power predictions}

Whilst these three issues discussed above are of importance, the issue of primary practical interest for paste piping design is the error in power prediction, if the design is performed using the incorrect approach (Slatter \& Fester, 2010). This situation is summarised for this example in Figure 22.

Figure 22 shows the pump operating points for both the laminar and turbulent design cases, as derived from the practical design case example presented above.

The three possible operating points arising from the different design approaches to the practical design case example are highlighted in Figure 22 and designated Point A, Point B and Point $C$. The coordinates and resulting motor power (brake power) requirements from each of these three operating points are presented in Table 7.

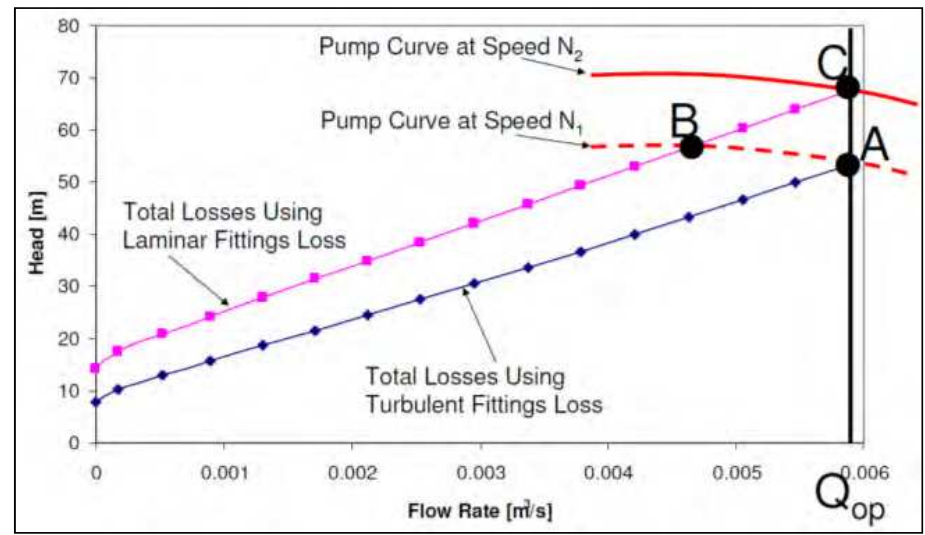

Fig. 22. Pump operating points for both the laminar and turbulent design cases 


\begin{tabular}{|l|c|c|c|}
\hline Point & A & B & C \\
\hline Q $[\mathrm{m} 3 / \mathrm{s}]$ & 0.0059 & 0.0046 & 0.0059 \\
\hline $\mathrm{H}[\mathrm{m}]$ & 53 & 57 & 67 \\
\hline Fluid Power $[\mathrm{kW}]$ & 4.6 & 3.9 & 5.8 \\
\hline Pump Efficiency & $65 \%$ & $50 \%$ & $55 \%$ \\
\hline Brake Power $[\mathrm{kW}]$ & 7.1 & 7.7 & 10.6 \\
\hline
\end{tabular}

Table 7. Pump operating point coordinates from Figure 22

If the design is performed using the incorrect approach (Slatter \& Fester, 2010), the (incorrect) design operating point will be at Point A for this example, as shown in Figure 22 and Table 7.

If the designer follows the information published by the authors (Fester et al., 2007; Mbiya et al., 2009), the (correct) design operating point will be at Point $C$ for this example, as shown in Figure 21 and Table 7.

This presents at least two problems of profound practical importance:-

1. If the designer follows the first (incorrect) approach, then Figure 22 shows that - in reality - the pump will actually operate, not at Point A, but at Point B, at pump speed $N_{1}$. Point $B$ presents an operating flow rate penalty exceeding $20 \%$ whilst being almost $10 \%$ under-powered, as shown in Table 7.

2. In order to achieve the desired flow rate, the operating point will need to move from Point B to Point C, i.e. the speed would need to be significantly increased to pump speed $\mathrm{N}_{2}$. This increase in pump speed will require $50 \%$ more brake power, as shown in Figure 22 and Table 7.

The important practical message here is that the pump motor would be $50 \%$ undersized.

All of these issues are further exacerbated by the shallow intersection angle which the laminar flow system curve presents to a centrifugal pump curve, as shown Figure 22. This will result in unstable operation, as small changes in head (i.e. small changes in material consistency) will result in significant changes in operating point flow rate.

As indicated by other laminar flow investigations over several decades (e.g. Edwards et al., 1985; Fester et al., 2008), all fittings show the $\mathrm{k}_{\mathrm{v}}$ values in laminar flow to be significantly greater than those in turbulent flow.

\section{Conclusions}

Minor losses are important in the efficient design of pipelines in laminar flow. The loss coefficients in laminar flow for all fittings are orders of magnitude greater than those in turbulent flow. The purely viscous driven flow regime is primarily at $\operatorname{Re}<10$, after which turbulence will be introduced that is dependent on the geometry of the fitting. For some fittings, the minima value obtained are very pronounced, especially for larger orifice ratios and larger valve sizes. For sudden contractions and long orifices, a smoother transition is 
observed. Dynamic similarity can be established for geometrically similar fittings using a Reynolds number that can accommodate the rheological parameters of the fluid. Pump sizing estimates for shorter lengths of pipelines with a number of fittings operating in laminar flow can be underpredicted by up to $50 \%$. The significance of the impact on pump sizing would therefore appear to be representative of other fittings in general, but focussed research to substantiate this is required.

\section{References}

Alderman, N.J. \& Heywood, N.I. (1996), The design, selection and application of valves for slurry pipeline service, Proc. Hydrotransport 13, Johannesburg, South Africa, 3-5 September.

Alderman, N.J. \& Heywood, N.I. (2004a). Improving slurry viscosity and flow curve measurements, Chemical Engineering Progress, Vol.101 (4), pp. 38-44

Alderman, N.J. \& Heywood, N.I. (2004b). Making accurate slurry flow curve measurements, Chemical Engineering Progress, Vol.101 (5), pp. 35-41

Alderman, N.J. (1997). Non-Newtonian Fluids: Guide to classification and characteristics, ESDU 97034, ESDU International plc, London

Banerjee T.K., Das M. \& Das S.K. (1994). Non-Newtonian liquid flow through globe and gate valves. Canadian Journal of Chemical Engineering, Vol.72, (Apr), pp. 207-211

Barnes, H. A. (2002). Viscosity, Institute of Non-Newtonian Fluid Mechanics, University of Wales, Aberystwyth

Bohra, L. K. (2004). Flow and Pressure Drop of Highly Viscous Fluids in Small Aperture Orifices. MSc thesis. Georgia, U.S.A: Georgia Institute of Technology

Bingham, E.C. (1922). Fluidity and Plasticity, McGraw-Hill, New York

Brown, N.P. \& Heywood, N.I. (1991). Slurry Handling: Design of Solid-Liquid Systems. Kluwer Publications, ISBN 1-85166-645-1, Dordrecht, Netherlands

Carreau P.J. (1968). PhD Thesis, Univ Wisconsin, Madison, 1968

Casson, N. (1959). A flow equation for pigmented-oil suspension for the printing ink type, In: Mill, C.C. (ed). Rheology of Dispersed Systems. pp. 84-104. Pergamon Press, New York

Chadwick, A.J. \& Morfett, J.C. 1993. Hydraulics in Civil and Environmental Engineering. ISBN 0 4191816 01. Taylor \& Francis Books Ltd, London

Crane, Co. (1999). Flow of Fluids Through Valves, Fittings and Pipe, Technical paper No. 410. Crane Co., Chicago, IL, USA

Cross, M.M. (1965). Rheology of non-Newtonian flow: equation for pseudoplastic systems, Journal of Colloid Science, Vol.20, pp. 417-437

de Waele, A. (1923). Oil Color, Chemical Association Journal, Vol.6, pp. 23-88

Edwards, M.F., Jadallah, M.S.M. and Smith, R. (1985). Head losses in pipe fittings at low Reynolds numbers, Chemical Engineering Research and Design, Vol.63, (January 1985) pp. $43-50$

Engineering Sciences Data Unit. 1989. Pressure Losses in Flow Through a Sudden Contraction of Duct Area. Data Item 89040.

ESDU. (2007). Incompressible Flow Through Orifice Plates-A Review of the Data in the Literature. London: Engineering science data unit. ISBN 978186246608 1, ISSN 0141-4011 
Fester V.G. \& Slatter P.T. (2009). Dynamic similarity for Non-Newtonian fluids in globe valves, Trans IChemE, Part A, Chemical Engineering Research and Design, Vol.87, pp. 291- 297, ISSN 0263-8762

Fester V.G., Chowdhury M.R. \& Iudicello F. (2010). Pressure loss and discharge coefficients for non-Newtonian fluids in long orifices, British Hydromechanics Research Group 18th International Conference on Slurry Handling and Pipeline Transport HYDROTRANSPORT 18, Rio de Janeiro, Sept 22-24, 2010, pp. 309-323. ISBN: 9781 855981195.

Fester V.G., Mbiya B.M., \& Slatter P.T. (2008), Energy losses of non-Newtonian fluids in sudden pipe contractions, Chemical Engineering Journal, Vol.145, No.1, pp. 57-63, ISSN 1385-8947

Fester, V.G., Kazadi, D.M., Mbiya, B.M. \& Slatter P.T. (2007). Loss coefficients for flow of Newtonian and non-Newtonian fluids through diaphragm valves, Trans IChemE, Part A, Chemical Engineering Research and Design, Vol.85 (A9), pp. 1314-1324

Govier, G.W. \& Aziz, K. (1972). The Flow of Complex Mixtures in Pipes, van Nostrand Reinhold Co.

Hanks, R. W.( 1979).The axial laminar flow of yield-pseudoplastic fluids in a concentric annulus. Ind. Eng. Chem. Proc. Des Dev, 18, pp. 488-493

Hasegawa, T., Suganuma, M., \& Watanabe, H. (1997). Anomaly of excess pressure drops of the flow through very small orifices. Physics of Fluids, Vol.9, pp. 1 - 3

Herschel, W.H. and Bulkley, R. (1926). Konsistenzmessungen von GummiBenzollosungen. Kolloid-Z, Vol.39, pp. 291-330

Heywood, N.I. \& Cheng, D.C-H. (1984). Comparison of methods for predicting head loss in turbulent pipeflow of non-Newtonian fluids. Trans. Institute for Measurement and . Control., Vol.6, pp. 33-45

Hooper, W.B. (1981). The two-K method predicts head losses in pipe fittings. Chemical Engineering, August, pp. 96-100

Idel'chik, I. E., Malyavskaya, G. R., Martynenko, O. G., \& Fried, E. (1994). Handbook of Hydraulic Resistance. CRC press, London

Jadallah, M.S.M. (1980). Flow in pipe fittings at low Reynolds numbers. Unpublished PhD thesis, University of Bradford, UK.

Jamison, D.K. \& Villemonte, J.R (1971). Junction losses in laminar and transitional flows. Journal of the Hydraulics Division, Proceedings of the American Society of Civil Engineers, HY 7, pp.1045-1063

Johansen, F.C. (1930). Flow through pipe orifices at low Reynolds numbers. Proceedings of the Royal Society of London, Series A, Vol.126, No.801, pp.231-245

Kabwe, A. M., Fester, V. G., \& Slatter, P. T. (2010). Prediction of non-Newtonian head losses through diaphragm valves at different opening positions. Chemical Engineering Research and Design, Vol. 88, pp. 959-970

King, R.P. 2002. Introduction to Practical Fluid Flow. ISBN 0-7506-4885-6, ButterworthHeinemann, Oxford

Laba, D. (1993). Rheological properties of Cosmetics and Toiletries, Marcel Dekker Inc., New York 
Lakshmana Rao, N.S. \& Shridharan, K. 1972. Orifice losses for laminar approach flow. ASCE Journal of Hydraulics Division, Vol.98, No.11, (November), pp. 2015-2034

Lakshmana Rao, N.S., Srhidharan, K. \& Alvi, S.H. (1977). Critical Reynolds Number for orifice and nozzle flows in pipes. Journal of Hydraulic Research, International Association for Hydraulic Research, Vol. 15, No. 2, pp. 167-178

Ma, T.W. (1987). Stability, rheology and flow in pipes, fittings and venturi meters of concentrated non-Newtonian suspensions, Unpublished PhD thesis, University of Illinois, Chicago

Massey, B.S. (1970). Mechanics of fluids, Second edition, van Nostrand Reinhold Co

Mbiya, B.M., Fester, V.G. \& Slatter P.T. (2009). Evaluating resistance coefficients of control diaphragm valves, The Canadian Journal of Chemical Engineering, Vol.87, pp. 704-714, ISSN 0008-4034

McNeil, D.A. \& Morris, S.D. (1995). A mechanistic investigation of laminar flow through an abrupt enlargement and nozzle and its application to other pipe fittings. Report EUR $16348 \mathrm{EN}$

Medaugh, F.W. \& Johnson, G.D. 1940. Investigation of the discharge and coefficients of small circular orifices. Civil Engineering, Vol.7, No.7, (July), pp. 422-424

Mika, L. (2011). Energy losses of ice slurry in pipe sudden contractions. Experimental Thermal and Fluid Science, Vol.35, pp. 939-947.

Miller, D.S. (1978). Internal flow systems, Cranfield, BHRA Fluid Engineering

Ntamba Ntamba, B.M. (2011). Non-Newtonian pressure loss and discharge coefficients for short square-edged orifice plates, Unpublished M.Tech. thesis, Cape Peninsula University of Technology, Cape Town.

Ostwald, W. (1925). Über die geschwindigkeitsfuncktion der viskosität disperser systeme I., Kolloid-Z., 36, pp. 99-117

Pal, R. and Hwang. C-Y. J. 1999. Loss coefficients for flow of surfactant-stabilised emulsions through pipe components. Trans. IChemE, Vol.77 (Part A): 685-691

Pienaar, V.G. \& Slatter, P.T. (2004). Interpretation of experimental data for fittings losses; 12th International Conference on Transport and Sedimentation of Solid Particles, pp. 537 - 546, ISBN 80-239-3465-1, Prague, Czech Republic September 20-24, 2004

Pienaar, V.G. (1998). Non-Newtonian fitting losses, Unpublished M.Tech. thesis, Cape Technikon, Cape Town

Roberts, G.P., Barnes, H.A \& Mackie, C. (2001). Using the Microsoft Excel 'solver' tool to perform non-linear curve fitting, using a range of non-Newtonian flow curves as examples, Applied Rheology, September/October

Schlichting H (1960), Boundary layer theory, 4th edition, McGraw-Hill, New York

Sisavath, S., Jing, X., Pain, C.C. \& Zimmerman, R.W. (2002). Creeping flow through axisymmetric sudden contraction or expansion. Journal of Fluids Engineering, (Trans. ASME), Vol.124, No.1, (March) pp. 273-278

Sisko, A.W. (1958), The flow of lubricating greases. Ind Engng Chem., Vol.50, pp. 17891792 
Slatter P T (1995), The laminar/turbulent transition of non-Newtonian slurries in pipes; 14th World Dredging Congress, Amsterdam, 14-17 November, 1995, ISBN 90-9008834-2 pp. 31-48

Slatter P T (1996); Turbulent flow of non-Newtonian slurries in pipes; J. Hydrol. Hydromech., Vol. 44, No.1, pp. 24-38

Slatter P T (1999); The laminar/turbulent transition prediction for non-Newtonian slurries, Proceedings of the International Conference "Problems in Fluid Mechanics and Hydrology", Academy of Sciences of the Czech Republic, Prague, June 23-26, 1999.ISBN 8023838245 pp. 247 - 256

Slatter P T (1999b); The role of rheology in the pipelining of mineral slurries, Min. Pro. Ext. Met. Rev., Vol 20, pp 281-300

Slatter PT (2011) The engineering hydrodynamics of viscoplastic suspensions. J. Particulate Science and Technology, Vol. 29, No.2, pp. 139-150

Slatter PT and Fester VG (2010); Fittings losses in Paste Flow Design, R.J.Jewel and A.B.Fourie (eds); Paste 2010,13th International Seminar on Paste and Thickened Tailings, Toronto, Canada;3-6 May 2010. pp. 303-310. ISBN 978-0-9806154-0-1

Steffe, J.F. (1996), Rheological methods in Food Process Engineering, 2nd ed., Freeman Press, Michigan

Streeter, V.L. \& Wylie, B. (1985). Fluid Mechanics, 6th edition, McGraw-Hill Inc., USA

Turian, R.M., Ma, T.W., Hsu, F.L.G., Sung, M.D.J. \& Plackmann, G.W. (1998). Flow of concentrated slurries: 2 . Friction losses in bends, fittings, valves and venturi meters. International Journal of Multiphase Flow, Vol.24, No.2, pp. 243-269.

Ward-Smith, A.J. 1976. Component interactions and their influence on the pressure losses in internal flow systems. Heat and Fluid Flow O ImechE, Vol.6, No. 2, pp. 79-88

Whitehouse, R.C. (1993). The Valve and Actuator User's Manual, British Valve Manufacturers' Association, Mechanical Engineering Publications, London. 


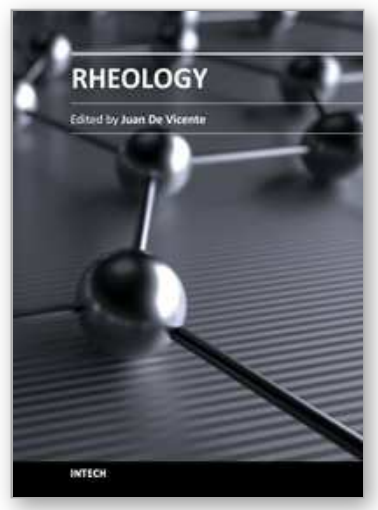

\author{
Rheology \\ Edited by Dr. Juan De Vicente
}

ISBN 978-953-51-0187-1

Hard cover, 350 pages

Publisher InTech

Published online 07, March, 2012

Published in print edition March, 2012

This book contains a wealth of useful information on current rheology research. By covering a broad variety of rheology-related topics, this e-book is addressed to a wide spectrum of academic and applied researchers and scientists but it could also prove useful to industry specialists. The subject areas include, polymer gels, food rheology, drilling fluids and liquid crystals among others.

\title{
How to reference
}

In order to correctly reference this scholarly work, feel free to copy and paste the following:

Veruscha Fester, Paul Slatter and Neil Alderman (2012). Resistance Coefficients for Non-Newtonian Flows in Pipe Fittings, Rheology, Dr. Juan De Vicente (Ed.), ISBN: 978-953-51-0187-1, InTech, Available from: http://www.intechopen.com/books/rheology/resistance-coefficients-for-non-newtonian-flows-in-pipe-fittings

\section{INTECH}

open science | open minds

\section{InTech Europe}

University Campus STeP Ri

Slavka Krautzeka 83/A

51000 Rijeka, Croatia

Phone: +385 (51) 770447

Fax: +385 (51) 686166

www.intechopen.com

\section{InTech China}

Unit 405, Office Block, Hotel Equatorial Shanghai

No.65, Yan An Road (West), Shanghai, 200040, China

中国上海市延安西路65号上海国际贵都大饭店办公楼405单元

Phone: +86-21-62489820

Fax: $+86-21-62489821$ 
(C) 2012 The Author(s). Licensee IntechOpen. This is an open access article distributed under the terms of the Creative Commons Attribution 3.0 License, which permits unrestricted use, distribution, and reproduction in any medium, provided the original work is properly cited. 